\title{
Formation and Reactivity of Electron-Precise B-B Single and Multiple Bonds
}

Merle Arrowsmith, Holger Braunschweig, * Tom E. Stennett

Abstract: Recent years have seen rapid advances in the chemistry of small molecules containing electron-precise boron-boron bonds. This review provides an overview of the latest methods for the controlled synthesis of B-B single and multiple bonds as well as the ever-expanding range of reactivity displayed by the latter.

\section{Introduction}

Despite the now ubiquitous use of diborane(4) reagents in organic synthesis, ${ }^{[1]}$ in particular in catalytic diboration ${ }^{[2]}$ and borylation reactions, ${ }^{[3]}$ only a handful of diboron compounds are actually commercially available, and their preparation still relies on rather inefficient multistep syntheses. The industrial synthesis of the two most widely used tetra(alkoxy)diboranes(4), bis(pinacolato)diboron $\left(\mathrm{B}_{2} \mathrm{Pin}_{2}\right)$ and bis(catecholato)diboron $\left(\mathrm{B}_{2} \mathrm{Cat}_{2}\right)$, from $\mathrm{BBr}_{3}$, for example, requires four steps, including a harsh reductive coupling step, and generates vast amounts of waste by-products. ${ }^{[4,5]}$ It is therefore not surprising that recent years have seen a surge in the design of new and improved ways of generating B-Bbonded compounds. ${ }^{[6,7]}$

In contrast to its right-hand neighbor, carbon, whose readiness to form homodinuclear single and multiple bonds is the basis of organic molecular and polymer chemistry, the element boron proves rather reluctant to form electron-precise bonds with itself. With a bond dissociation energy $\left(D_{0(\mathrm{~B}-\mathrm{B})}=293 \mathrm{~kJ} \mathrm{~mol}^{-1}\right)$ intermediate between that of carbon $\left(D_{0(\mathrm{C}-\mathrm{C})}=\right.$ $\left.345 \mathrm{~kJ} \mathrm{~mol}^{-1}\right)$ and silicon $\left(D_{0(\mathrm{Si}-\mathrm{Si})}=222 \mathrm{~kJ} \mathrm{~mol}^{-1}\right)$, both known to form stable homocatenanes,${ }^{[8,9]}$ all-boron chains would theoretically be thermodynamically stable, were it not for the propensity of B-B bonds to undergo facile cleavage in favor of significantly more stable bonds such as B-O $\left(D_{0}=536 \mathrm{~kJ} \mathrm{~mol}^{-1}\right)$, B-N $\left(D_{0}=446 \mathrm{~kJ} \mathrm{~mol}^{-1}\right)$ or B-C $\left(D_{0}=372 \mathrm{~kJ}\right.$ $\mathrm{mol}^{-1}$ ). Moreover, the electron-deficient nature of three-coordinate boron results in kinetic instability. Unless stabilized electronically - using $\pi$-basic (e.g. amino, alkoxy) substituents or sterically shielded by bulky substituents, boron compounds tend to avoid $\mathrm{sp}^{2}$ hybridization in favor of multicenter bonding. While $\mathrm{B}_{2} \mathrm{H}_{4}$ has been calculated to exist as an equilibrium 
mixture of the staggered $D_{2 d}$ and doubly-bridged $C_{2 v}$ structural isomers and only once been transiently observed in its $C_{2 v}$ form, ${ }^{[10]}$ larger polyboranes of the formula $\mathrm{B}_{\mathrm{n}} \mathrm{H}_{\mathrm{m}}$ all favor nonclassical, i.e. electron-deficient structures with bridging hydrides. ${ }^{[11]}$ For $n \geq 4$ additional $\pi$ bonding stabilization is provided by three-dimensional cluster formation. ${ }^{[12]}$

Table 1. Early efforts in B -B bond formation and catenation via reductive coupling.

\begin{tabular}{|c|c|c|c|c|}
\hline Year & Author & Haloborane reagent(s) & $\begin{array}{l}\text { Reducing agent, } \\
\text { solvent, } T\end{array}$ & $\begin{array}{l}\text { Product(s) } \\
\text { (isolated yield) }\end{array}$ \\
\hline 1925 & Stock & $\mathrm{BCl}_{3}$ & electrical $\operatorname{arc}(\mathrm{Zn}), 0{ }^{\circ} \mathrm{C}$ & $\mathrm{B}_{2} \mathrm{Cl}_{4}(<1 \%)$ \\
\hline 1949 & Schlesinger & $\mathrm{BCl}_{3}$ & glow discharge $(\mathrm{Hg}), 0{ }^{\circ} \mathrm{C}$ & $\mathrm{B}_{2} \mathrm{Cl}_{4}(50 \%)$ \\
\hline 1960 & Brotherton & $\mathrm{B}\left(\mathrm{NMe}_{2}\right)_{2} \mathrm{Br}$ & $\mathrm{Na}$, toluene, $110^{\circ} \mathrm{C}$ & $\mathrm{B}_{2}\left(\mathrm{NMe}_{2}\right)_{4}(80.5 \%)$ \\
\hline 1970 & Nöth & $\mathrm{B}\left(\mathrm{NMe}_{2}\right)_{2} \mathrm{Cl}+\mathrm{B}_{2}\left(\mathrm{NMe}_{2}\right)_{3} \mathrm{Cl}$ & $\mathrm{Na} / \mathrm{K}$, toluene, $\mathrm{rt}$ & $\mathrm{B}_{3}\left(\mathrm{NMe}_{2}\right)_{5}(5.5 \%)$ \\
\hline & & $\mathrm{B}_{2}\left(\mathrm{NMe}_{2}\right)_{3} \mathrm{Cl}$ & $\mathrm{Na} / \mathrm{K}$, toluene, $\mathrm{rt}$ & $\mathrm{B}_{4}\left(\mathrm{NMe}_{2}\right)_{6}(10 \%)$ \\
\hline & & $2 \mathrm{~B}_{2}\left(\mathrm{NMe}_{2}\right)_{3} \mathrm{Cl}+\mathrm{B}_{3}\left(\mathrm{NMe}_{2}\right)_{4} \mathrm{Cl}$ & $\mathrm{Na} / \mathrm{K}$, toluene, rt & $\begin{array}{l}\mathrm{B}_{4}\left(\mathrm{NMe}_{2}\right)_{6}(15 \%) \\
+\mathrm{B}_{5}\left(\mathrm{NMe}_{2}\right)_{7}(58 \%)\end{array}$ \\
\hline 1980 & Nöth & $\mathrm{B}\left(\mathrm{NMe}_{2}\right)_{2} \mathrm{Cl}$ & $\mathrm{Na} / \mathrm{K}$, toluene, $\mathrm{rt}$ & $\begin{array}{l}\mathrm{B}_{2}\left(\mathrm{NMe}_{2}\right)_{4}(>90 \%) \\
+\mathrm{B}_{6}\left(\mathrm{NMe}_{2}\right)_{8}(\mathrm{a} \text { few crystals })\end{array}$ \\
\hline 1982 & Berndt & $\mathrm{B}_{2} t \mathrm{Bu}_{2} \mathrm{Cl}_{2}$ & $\mathrm{Na} / \mathrm{K}$, thf, rt & $\begin{array}{l}\text { closo }-\mathrm{B}_{4} t \mathrm{Bu}_{4}(-) \\
+\left[\text { cyclo- }-\mathrm{B}_{4} t \mathrm{Bu}_{4}\right]^{\bullet-}(-)\end{array}$ \\
\hline 1991 & Baudler & $\mathrm{B}\left(\mathrm{NEt}_{2}\right) \mathrm{Cl}_{2}$ & $\mathrm{~K}$, cyclohexane, $80^{\circ} \mathrm{C}$ & $\begin{array}{l}\text { cyclo- } \mathrm{B}_{3}\left(\mathrm{NEt}_{2}\right)_{3}(20-25 \%) \\
+ \text { cyclo }-\mathrm{B}_{4}\left(\mathrm{NEt}_{2}\right)_{4}(-) \\
+ \text { cyclo }-\mathrm{B}_{6}\left(\mathrm{NEt}_{2}\right)_{6}(0.5 \%) \\
+ \text { closo }-\mathrm{B}_{6}\left(\mathrm{NEt}_{2}\right)_{6}(\text { variable })\end{array}$ \\
\hline 1991 & Paetzold \& Boese & $\mathrm{B} t \mathrm{BuF}_{2}$ & $\mathrm{Na} / \mathrm{K}$, pentane, $36{ }^{\circ} \mathrm{C}$ & closo $-\mathrm{B}_{4}(t \mathrm{Bu})_{4}(26 \%)$ \\
\hline
\end{tabular}

The first synthesis of an electron-precise diborane(4) was that of $\mathrm{B}_{2} \mathrm{Cl}_{4}$ from $\mathrm{BCl}_{3}$ by arc discharge between a $\mathrm{Zn}$ anode and an $\mathrm{Al}$ cathode under $\mathrm{N}_{2}$ at low temperature. ${ }^{[13]}$ This method was later significantly improved upon by Schlesinger and co-workers using a glow discharge between mercury electrodes, which enabled the synthesis of $\mathrm{B}_{2} \mathrm{Cl}_{4}$ on a multi-gram scale. ${ }^{[14]}$ Unlike $\mathrm{B}_{2} \mathrm{H}_{4}$, diboron tetrahalides were shown to display a classical planar $D_{2 h}$ alkene-like structure. ${ }^{[15]}$ Above $0{ }^{\circ} \mathrm{C}, \mathrm{B}_{2} \mathrm{Cl}_{4}$ was found to decompose to $\mathrm{B}_{4} \mathrm{Cl}_{4}$, which, rather than a classical cyclotetraborane structure, adopts a more stable non-classical tetrahedrane structure in the solid state, ${ }^{[16]}$ though ${ }^{11} \mathrm{~B}$ NMR data and calculations suggest the existence of an electron-precise cyclo-tetrachlorotetraborane isomer in solution. ${ }^{[17,18]}$

The $\pi$-donor stabilization afforded by dialkylamino substituents enabled the synthesis of the first bench-stable diborane(4), $\mathrm{B}_{2}\left(\mathrm{NMe}_{2}\right)_{4}$, through reductive coupling of $\left(\mathrm{Me}_{2} \mathrm{~N}\right)_{2} \mathrm{BCl} .^{[4]}$ Inspired by this methodology, Nöth and co-workers succeeded in isolating several higher electron-precise oligoboranes of the formula $\left[\mathrm{B}_{\mathrm{n}}\left(\mathrm{NR}_{2}\right)_{\mathrm{n}+2}\right]$ through reductive coupling of various (dialkylamino)haloboranes, culminating in the synthesis of 
hexakis(dimethylamino)cyclohexaborane in $1980 .{ }^{[17,19]}$ In contrast, kinetically stabilized $\mathrm{B}_{4} t \mathrm{Bu}_{4}$, obtained by reduction of $\mathrm{B} t \mathrm{BuF}_{2}$ or $\mathrm{B}_{2} t \mathrm{Bu}_{2} \mathrm{Cl}_{2}$, presents an electron-deficient tetrahedrane structure ${ }^{[20]}$ and can be further reduced to the radical anion $\left[\mathrm{B}_{4} t \mathrm{Bu}_{4}\right]^{-}$, the EPR spectrum of which suggests a classical butterfly structure. ${ }^{[21]}$

Scheme 1. Selective synthesis of a triboracyclopropenyl dianion by reductive coupling

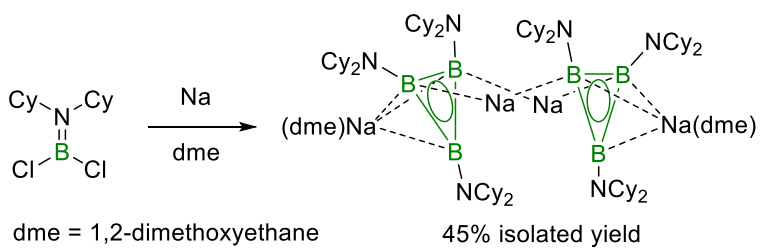

The yield and product distribution of these reductive couplings are highly sensitive to changes in substitution pattern and reaction conditions. In this area, the selectivity of the recently reported reductive trimerization of dicyclohexylaminodichloroborane to the corresponding Hückel 2-electron $\pi$-aromatic triboracyclopropenyl dianion, $\left[\mathrm{B}_{3}\left(\mathrm{NCy}_{2}\right)_{3}\right]^{2-}$, remains an exception (Scheme 1). ${ }^{[22]}$ Despite numerous attempts, no rational method to predict or control the degree of boron catenation, or the selectivity for classical over nonclassical polyboranes, has been found. The longest classical oligoboranes isolated to date, linear $\mathrm{B}_{6}\left(\mathrm{NMe}_{2}\right)_{8}{ }^{[19]}$ and cyclic $\mathrm{B}_{6}\left(\mathrm{NR}_{2}\right)_{6}(\mathrm{R}=\mathrm{Me}, \mathrm{Et}),{ }^{[17,23]}$ are only formed as negligible byproducts of otherwise unselective reductive coupling reactions. While the exact mechanism of these reactions is still unclear, the generation of highly reactive boryl radical and/or borylene intermediates tends to lead to unwanted side-reactions such as radical hydrogen abstraction from solvent or borylene insertion into $\mathrm{C}-\mathrm{H}$ and $\mathrm{C}-\mathrm{C}$ bonds, as observed, for example, by Power and co-workers in their attempt to synthesize doubly-bonded diborenes stabilized by bulky terphenyl groups ( 
Scheme 2). ${ }^{[24]}$

Recent years have seen an expansion of the main-group chemist's toolbox for the synthesis of electron-precise B-B single bonds beyond these Wurtz-type coupling reactions, while better control of reduction chemistry has enabled access to B-B multiply-bonded systems. ${ }^{[7 \text {, }}$ ${ }^{25]}$ These new synthetic methods, as well as early forays into the reactivity of B-B multiple bonds, will be discussed in this review. 
Scheme 2. Side reactions of boryl radical and borylene intermediates in the attempted reductive coupling of an aryldihaloborane

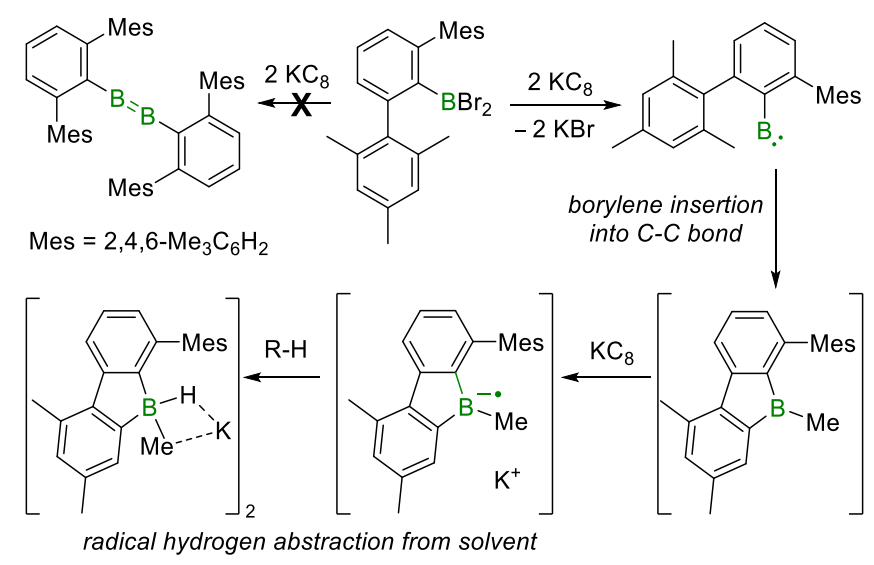

\section{Recent advances in the controlled synthesis of $B-B$ single bonds}

\subsection{Metal-templated borylene coupling}

Terminal and bridging transition metal borylenes have long been considered ideal sources of free borylene for subsequent B-element bond forming reactions. In 2002 our group reported the first photoinduced B-B coupling reaction from the chloroborylene-bridged dimanganese complex, 1, under CO atmosphere (Scheme 3a). ${ }^{[26]}$ The reaction, yielding nonclassical nido-metallaborane, 2, with a B-B bond length of 1.695(7) $\AA$, was postulated to proceed via the dimerization of a mononuclear terminal borylene intermediate. ${ }^{[27]}$

Despite rapid advances in the synthesis and variety of transition metal borylene complexes, however, the formation of B-B bonds by borylene coupling remains a rare phenomenon. The most notable example remains the iron-templated catenation of four boron atoms presented in Scheme $3 b .{ }^{[28]}$ Borylene transfer from $\left[(\mathrm{OC})_{5} \mathrm{Mo}=\mathrm{BN}\left(\mathrm{SiMe}_{3}\right)_{2}\right]$ to $\left[(\mathrm{OC})_{3}\left(\mathrm{Me}_{3} \mathrm{P}\right) \mathrm{Fe}=\mathrm{B}(\mathrm{Dur})\right]$ (3; Dur $=2,3,5,6$-tetramethylphenyl) resulted in the bis(borylene) complex $\left[(\mathrm{OC})_{3} \mathrm{Fe}\left(\mathrm{BN}\left(\mathrm{SiMe}_{3}\right)_{2}\right)_{2}\right], 4 .{ }^{11} \mathrm{~B} \mathrm{NMR}$ spectroscopy, X-ray crystallography [B-Fe-B 65.9 B-B 1.982(3) $\AA$ ] and theoretical calculations suggested the presence of a $\sigma$-bond (Wiberg Bond Index: 0.78 ) between the two boron atoms of 4 . This is in stark contrast to the related iridium bis(borylene) complex, $\left[\left(\eta^{5}-\mathrm{C}_{5} \mathrm{Me}_{5}\right) \operatorname{Ir}\left(\mathrm{BN}\left(\mathrm{SiMe}_{3}\right)_{2}\right)_{2}\right]$, in which the amidoborylene units also adopt a cis-configuration but with a much larger B-M-B angle of $78.4^{\circ}$ and B-B distance of $2.36 \AA$ precluding the existence of a B-B bond. ${ }^{[29]}$ DFT calculations by Pandey later showed that the degree of B-B bonding in group 9 cis-bis(amidoborylenes) increases from $\mathrm{Ir}$ to $\mathrm{Co},{ }^{[30]}$ yet without ever reaching the degree observed in 4. Under photolytic conditions, the iron bis(borylene) complex $\mathbf{4}$, first underwent dimerization to diiron species 5 
by loss of one CO ligand. Subsequent heating under a $\mathrm{CO}$ atmosphere led to the formation of the iron tetraboranediyl complex 6 with loss of, presumably, $\left[\mathrm{Fe}(\mathrm{CO})_{5}\right]$. Crystallographic and theoretical data evidenced a formal single bond for the inner B-B bond of the planar tetraboranediyl fragment [1.686(6) $\AA$ ], while the outer B-B $\sigma$-bonds [1.792(6), 1.814(6) $\AA$ ] are weakened by strong $\sigma_{\mathrm{BB}} \rightarrow \mathrm{Fe}$ donation to the metal center (Wiberg Bond Index: 0.86, 0.87). Similarly, reaction of 4 with $\mathrm{PCy}_{3}$ led to the formation of compound 7 , resulting from B-B $\sigma$-bond formation [1.646(4) $\AA$ ] concomitant with B-C catenation involving one of the CO ligands. ${ }^{[31]}$ Further irradiation and treatment with a smaller phosphine base, $\mathrm{PEt}_{3}$, led to a second $\mathrm{B}-\mathrm{CO}$ bond formation, yielding complex 8. Analogous to the $\mathrm{B}_{4}$ framework in complex $\mathbf{6}$, the $\mathrm{OC}-\mathrm{B}-\mathrm{B}-\mathrm{CO}$ framework of $\mathbf{8}$ is planar and the $\mathrm{B}-\mathrm{B}$ bond presents clear single bond character [1.655(5) $\AA]$, as supported by DFT calculations. Crystallographic and theoretical analysis also showed a more extensive weakening of the OC-BN $\sigma$-bond [2.030(5) $\AA]$ than of the OC-BC $\sigma$-bond [1.692(5) $\AA$ ] due to the stronger $\sigma$-donor and $\pi$-acceptor properties of the former.

Initial attempts to remove these metal-templated diborane- and tetraboranediyl fragments from their metal centers through photolysis or addition of bases have thus far proven unsuccessful and no other examples of B-B bond formation from metal borylenes have been observed to date.

Scheme 3. Base- and photoinduced B-B bond forming reactions of metal borylenes.
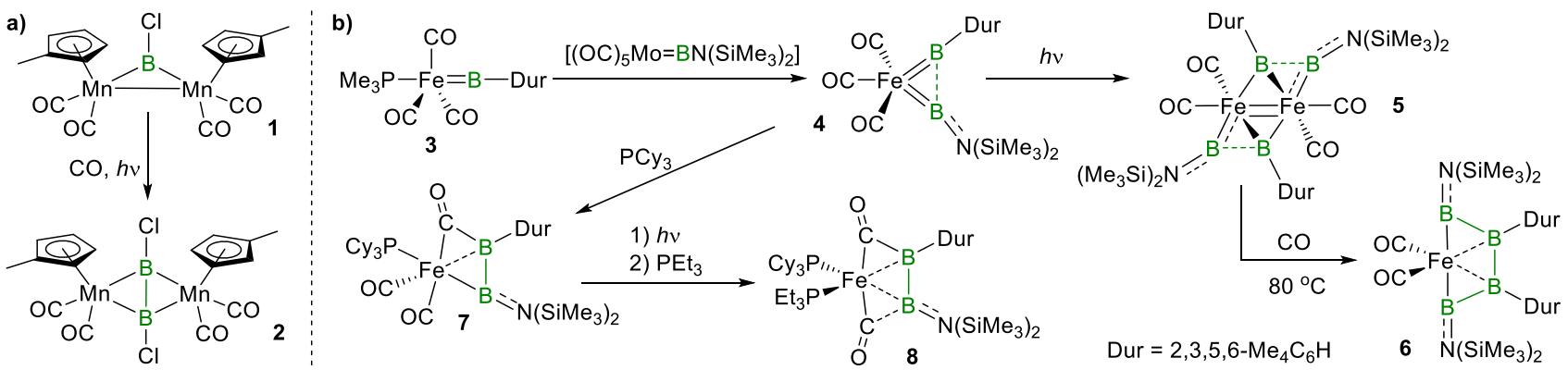

\subsection{Dehydrogenative coupling of boranes}

With the growing interest in low-weight hydrogen storage materials, research into amineborane dehydrocoupling has soared over the last decade. ${ }^{[32]}$ While the dehydrocoupling of protic (e.g. $\mathrm{R}_{2} \mathrm{NH}, \mathrm{R}_{2} \mathrm{PH}, \mathrm{ROH}$ ) and hydridic (e.g. $\mathrm{R}_{2} \mathrm{BH}, \mathrm{R}_{3} \mathrm{SiH}$ ) substrates is promoted by the respective polarization of the $\left[\mathrm{A}^{\delta-}-\mathrm{H}^{\delta^{+}}\right]$and $\left[\mathrm{B}^{\delta^{+}-}-\mathrm{H}^{\delta-}\right]$ bonds involved, and 
thermodynamically driven by the formation of strong A-B bonds, catalytic homonuclear dehydrocoupling had, until recently, only been developed for group 14 and 15 substrates. ${ }^{[8]}$

In the 1980s Sneddon and co-workers first reported the $\mathrm{PtBr}_{2}$-catalyzed dehydrogenative coupling of polyhedral carboranes and boranes, yielding linked-cage compounds in a highly selective manner under mild reaction conditions. ${ }^{[33]}$ More recently, Himmel and co-workers showed that a dimeric bicyclic guanidinate borane, 9, in which the boron atoms are preorganized for B-B bond formation, undergoes thermal or transition-metal-catalyzed intramolecular dehydrocoupling to the bis(guanidinate)-bridged 1,2-dihydrodiborane(6) 10 (Scheme 4). ${ }^{[34]}$ The reaction, however, remains limited to this one specific substrate.

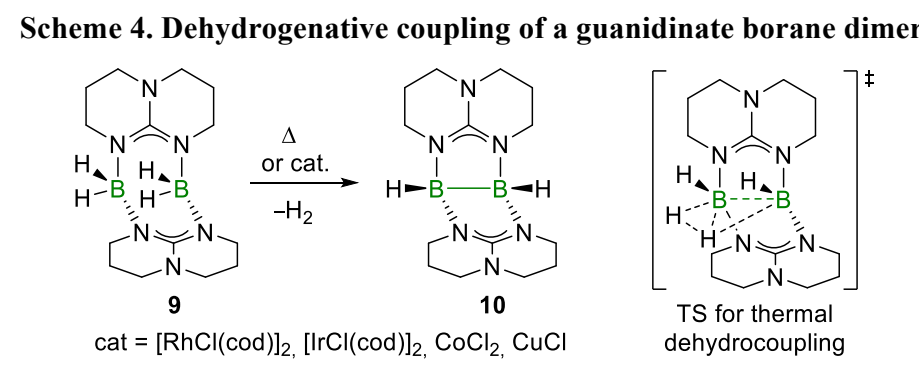

Motivated by the desire to find a more atom-efficient route to the widely used diborane(4) reagents, $\mathrm{B}_{2}$ pin 2 and $\mathrm{B}_{2} \mathrm{Cat}_{2}$, in 2010 our group successfully accomplished the first synthetically viable dehydrogenative coupling of pinacolborane (HBPin) and catecholborane (HBCat) to the corresponding diboranes(4) using homogeneous group 10 transition metal precatalysts (Scheme 5a). ${ }^{[35]}$ Prior to this, Marder and co-workers had already observed the formation of small amounts of $\mathrm{B}_{2} \mathrm{Pin}_{2}$ from HBPin as a by-product during the rhodiumcatalyzed synthesis of boronate esters. ${ }^{[36]}$ While homogeneous catalysis only provided low turnover numbers $\left(\mathrm{TON}_{\max }=106\right)$, the use of a heterogeneous catalyst (Pt on alumina, 0.006 mol\%) led to significant improvements (Scheme 5a). The competitive oxidative addition of the diborane(4) products to the catalyst at higher turnover numbers, which quickly led to a dramatic decrease in reaction rate and maximum yields of $5 \%$, was avoided by continuous removal of the diborane products by Soxhlet extraction, resulting in a TON increase by three orders of magnitude $\left(\mathrm{TON}_{\max }=11,600\right)$. Though the reaction was also shown to proceed with group 4 catalysts, the latter provided much lower TONs. ${ }^{[37]}$

Through stoichiometric studies, using a model $\left[\left(\left(\mathrm{CyCH}_{2}\right)_{3} \mathrm{P}\right)_{2} \mathrm{Pt}\right]$ precursor designed to provide flexible steric bulk, two catalytic intermediates could be identified: a transhydridoboryl $\mathrm{Pt}^{\mathrm{II}}$ complex, 11, resulting from the reversible oxidative addition of HBCat, and a cis-bis(boryl) $\mathrm{Pt}^{\mathrm{II}}$ complex, 12, obtained by the reversible reaction of $\mathbf{1 1}$ with excess HBCat 
(Scheme 5b). ${ }^{[38]}$ Furthermore, an earlier study had evidenced scrambling of $\mathrm{B}_{2} \mathrm{Cat}_{2}$ and $\mathrm{B}_{2} \mathrm{Cat}^{\prime}{ }_{2}\left(\mathrm{Cat}^{\prime}=4\right.$-tert-butylcatecholato $)$ in the presence of $\left[\left(\mathrm{Cy}_{3} \mathrm{P}\right)_{2} \mathrm{Pt}\right]$, as evidenced by the formation of $\mathrm{B}_{2}$ CatCat' and the mixed cis-bis(boryl) $\mathrm{Pt}^{\mathrm{II}}$ complex, 14. These findings suggest both reversible oxidative addition of diborane and the existence of a tetraboryl $\mathrm{Pt}^{\mathrm{IV}}$ intermediate (Scheme 5c). ${ }^{[39]}$ This result and further theoretical studies led to the postulation that the catalytic dehydrocoupling of HBPin and HBCat proceeds via a dihydrobis(boryl) $\mathrm{Pt}^{\mathrm{IV}}$ intermediate.

With each step of the dehydrocoupling reaction being reversible, the hydrogenation of $\mathrm{B}_{2} \mathrm{Pin}_{2}, \mathrm{~B}_{2} \mathrm{Cat}_{2}$ and $\mathrm{B}_{2} \mathrm{npg}_{2}(\mathrm{npg}=$ neopentylglycol) to the corresponding hydroboranes was achieved at room temperature under 1 bar of $\mathrm{H}_{2}$ using a heterogeneous $\mathrm{Pd} / \mathrm{C}$ catalyst. ${ }^{[40]} \mathrm{A}$ similar method had already been employed in one isolated instance by the group of Hartwig to generate deuterated DBPin by iridium-catalyzed deuteration of $\mathrm{B}_{2} \mathrm{Pin}_{2}{ }^{[41]}$

Scheme 5. Catalytic dehydrocoupling of pinacol- and catecholborane: mechanistic studies.

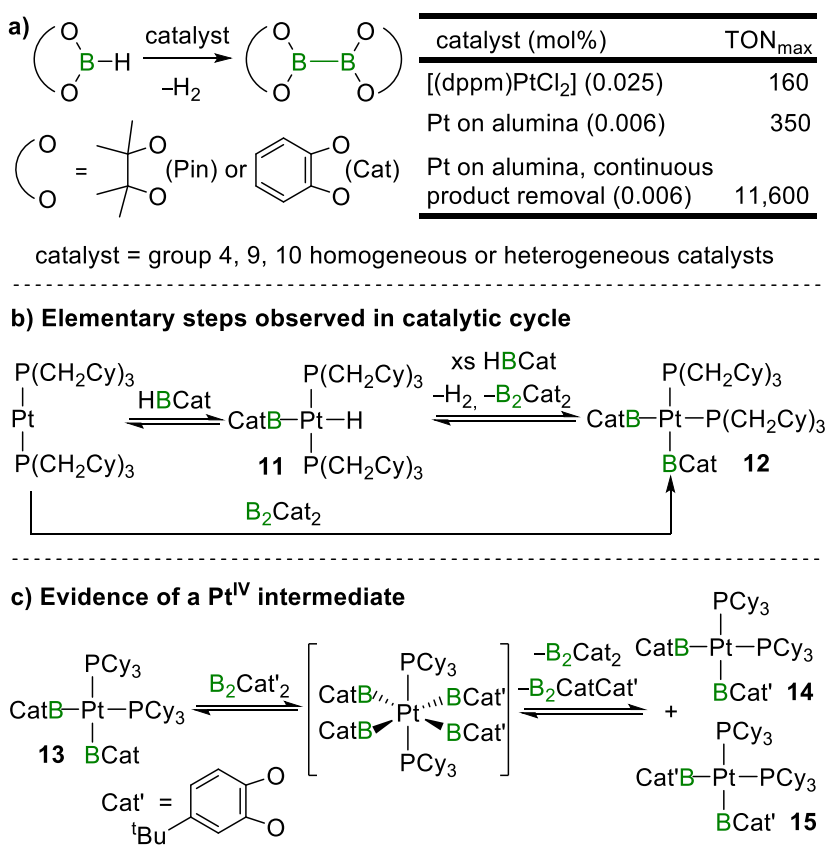

More recent attempts by our group to extend this chemistry to the dehydrogenative coupling of dihydroboranes met with mitigated success. Reaction of equimolar amounts of DurBH $\mathrm{H}_{2}$ with $\left[\left(\mathrm{Cy}_{3} \mathrm{P}\right)_{2} \mathrm{Pt}^{0}\right]$ in boiling thf for 3 hours resulted in a mixture of compounds, including small amounts of a $\left(\mathrm{Cy}_{3} \mathrm{P}\right)_{3} \mathrm{Pt}_{3}$-supported diborene, compound 16, resulting from double dehydrocoupling of two borane molecules, and compound 17 , comprising a $\left(\mathrm{Cy}_{3} \mathrm{P}\right)_{4} \mathrm{Pt}_{4}$ butterfly core capped by a tetrabridging durylborylene and presenting two opposite edges bridged by $\mu_{2}$-durylborylene units (Scheme 6). ${ }^{[42]}$ The main products of this reaction, however, were the $\mathrm{Pt}^{\mathrm{II}}$ dihydride complex $\left[\right.$ trans $\left.-\left(\mathrm{Cy}_{3} \mathrm{P}\right)_{2} \mathrm{PtH}_{2}\right]$ and the phosphine borane 
adduct $\left[\left(\mathrm{Cy}_{3} \mathrm{P}\right) \mathrm{DurBH}_{2}\right]$. Alongside the latter, reaction of two equivalents of $\mathrm{DurBH}_{2}$ with $\left[\left(\mathrm{Cy}_{3} \mathrm{P}\right)_{2} \mathrm{Pt}^{0}\right]$ for 6 minutes in boiling thf led to the formation of complex $\mathbf{1 8}$ (41\% yield) presenting a $\left(\mathrm{Pt}^{\mathrm{II}}\right)_{2} \mathrm{~B}_{2}$ core with two terminal $\mathrm{Pt}-\mathrm{H}$ bonds and a $\mu$-hydrido-bridged $\mathrm{Pt}-\mathrm{Pt}$ bond supporting a B-B single bond [1.648(7) $\AA$ ] bearing two terminal duryl substituents and a bridging hydride. While further heating of $\mathbf{1 8}$ did lead to monodehydrogenation, this was also accompanied by B-B cleavage and formation of complex 19, comprising a $\mu_{2}$-durylborylene bridged $\left(\mathrm{Cy}_{3} \mathrm{P}\right)_{2} \mathrm{Pt}_{2}$ supporting a neutral $\mathrm{DurBH}_{2}$ fragment. Unfortunately, the formation of these cluster-type compounds also blocked any catalytic B-B-bond-forming reactivity by dehydrogenative coupling.

Scheme 6. Stoichiometric dehydrocoupling of $\mathrm{DurBH}_{2}$ at Pt.

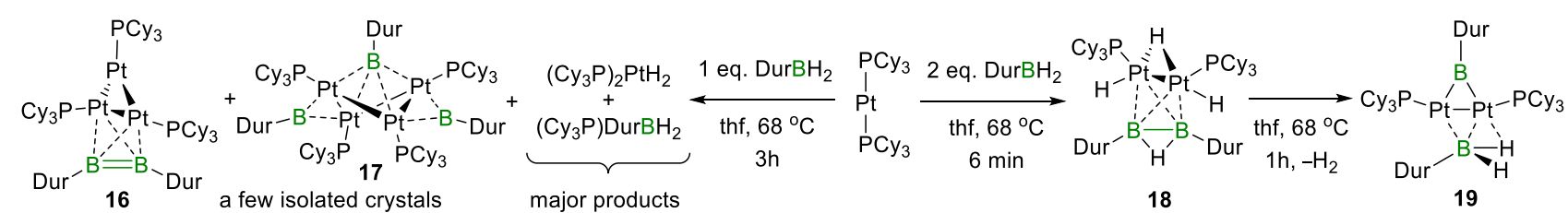

Further $\mathrm{B}-\mathrm{B}$ catenation by hydroboration of $\mathrm{B}=\mathrm{B}$ double bonds will be discussed in a subsequent section on the reactivity of boron-boron multiple bonds (vide infra). 
Table 2. B-B distances, bond orders ( ${ }^{\mathrm{a}} \mathrm{WBI},{ }^{\mathrm{b}} \mathrm{MBO}$ calculated on model compound $\left.\left.\left[\left(\mathrm{Me}_{3} \mathrm{P}\right)_{2} \mathrm{Pt}_{\left(\mathrm{B}_{2}\right.} \mathrm{Ph}_{2}\right)\right]\right)$ and ${ }^{11} \mathrm{~B} \mathrm{NMR}$ shifts in transition metal-bound B-B bonded species.

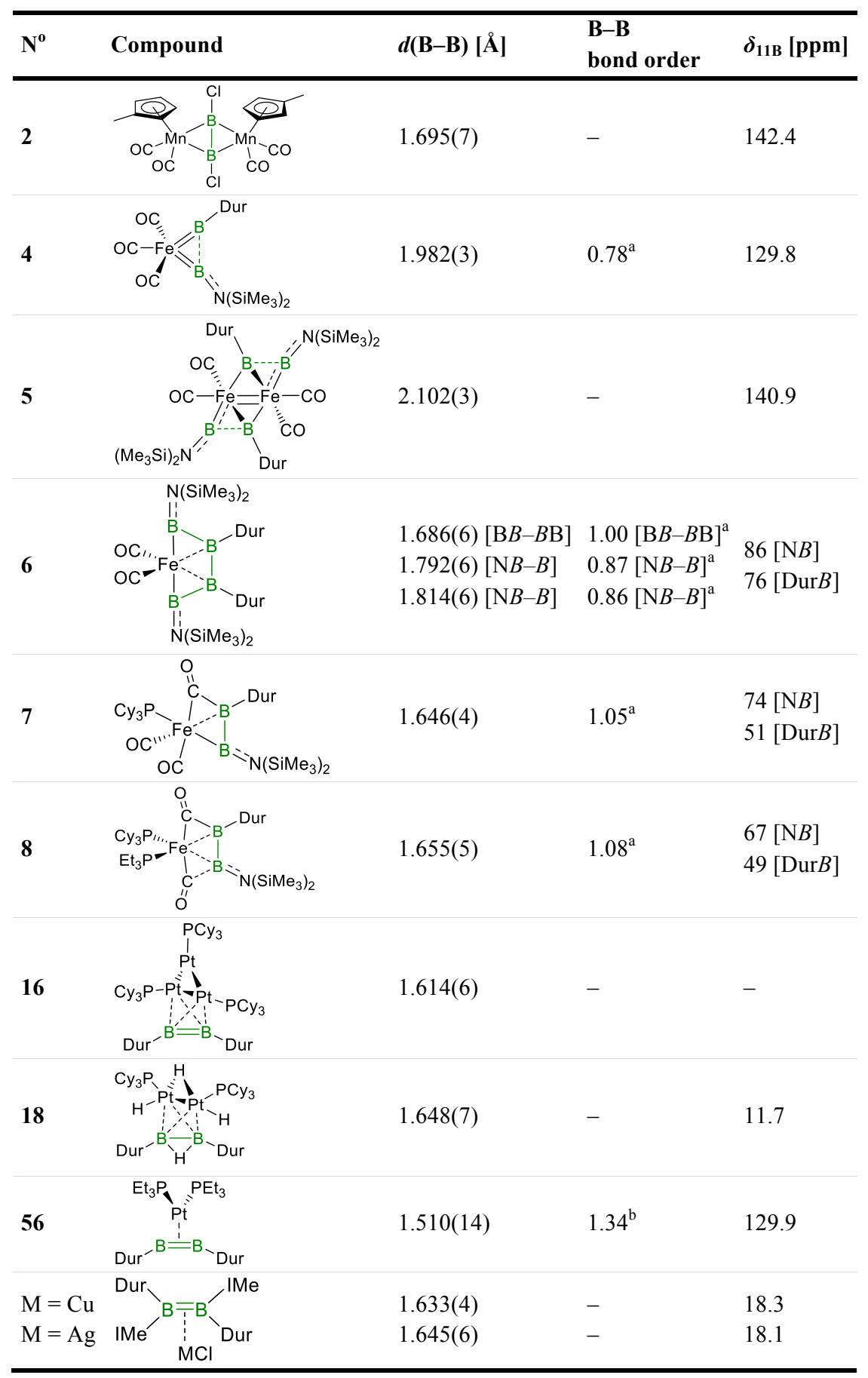

\subsection{Selective reductive coupling of arylboranes}

Despite some progress on the front of borylene and dehydrogenative coupling, reductive Wurtz-type coupling still remains the most widely used route towards new diborane(4) derivatives, which are particularly sought-after for catalytic diborations and borylations. ${ }^{[2],[3]}$ In 2014 Tamao and Matsuo reported the first 1,2-dihydrodiborane(4) species, [(Mpind)BH $]_{2}$ 
(20, Mpind = 1,1,7,7-tetramethyl-3,3,5,5-tetrapropyl-s-hydrindacen-4-yl, Scheme 7). ${ }^{[43]}$ The compound, obtained from the reduction of the aryldihydroborane dimer [(Mpind)BH $\left.\mathrm{BH}_{2}\right]_{2}$ with lithium, followed by two consecutive $\mathrm{LiH}$ abstraction steps, was isolated as the staggered $D_{2 d}$ isomer and is the first diborane(4) to display terminal hydrogens (Scheme 7). The steric requirements of the supporting aryl ligand Mpind play a crucial role in enabling access to the electron-precise 1,2-dihydrodiborane(4); indeed, the slightly less hindered analogue $[(\text { Eind }) B H]_{2}(\mathbf{2 1}$, Eind = 1,1,3,3,5,5,7,7-octaethyl-s-hydrindacen-4-yl), had been isolated as a doubly hydrogen-bridged butterfly-shaped diborane. ${ }^{[44]}$

Scheme 7. Synthesis of 1,2-dihydrodiboranes by reductive coupling of aryldihydromonoboranes.

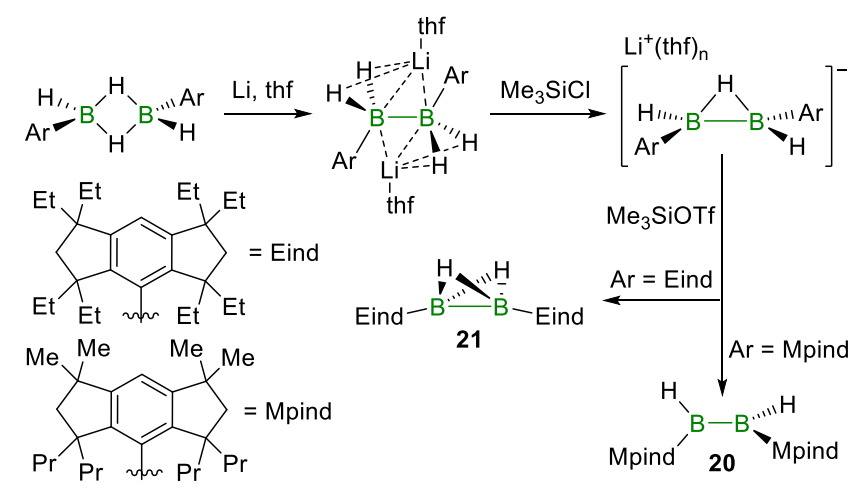

More recently, Wagner and co-workers demonstrated the variety of B-B bonds that may be obtained by reduction of the hydride-bridged bis(2,2' -biphenyl)diborane 22 , a compound ideally preorganized for reductive B-B coupling ( 
Scheme 8$).{ }^{[45]}$ While reduction with a large excess of $\mathrm{Li}$ in thf yielded the dianionic 8b,16b-(diborata)dibenzo[ $g, p]$ chrysene 23 , which presents a formal $\mathrm{B}=\mathrm{B}$ double bond [1.641(6), 1.627(6) $\AA]$, reduction with 2 or 4 molar equivalents of lithium naphthalenide in thf yielded two isomeric diborane(6) dianions displaying B-B single bonds, compounds 24 and 25, respectively $[\mathrm{B}-\mathrm{B}: \mathbf{2 4} 1.810(5), \quad \mathbf{2 5} 1.789(7) \quad \AA] .{ }^{[46]}$ Furthermore, the 1,1dihydrodiborane(6) dianion $\mathbf{2 4}$ was found to isomerize to the 1,2-dihydrodiborane(6) dianion 25 at moderately elevated temperatures. Switching to a large excess of $\mathrm{KC}_{8}$ as the reducing agent afforded a third bis(biphenyl)-bridged 1,2-dihydrodiborane(6) dianion, 26 [B-B $1.755(4) \AA]$, while reduction with a single equivalent of $\mathrm{KC}_{8}$ gave access to a monoanionic bis(biphenyl)-bridged $\mu$-hydridodiborane, compound 27 [1.651(6) $\AA]$. This work demonstrates once more the sensitivity of the outcome of reductive couplings to various factors such as temperature, the nature of the reducing agent and stoichiometry. 
Scheme 8. A range of B-B-bonded products obtained under various reaction conditions for the reduction of 22.

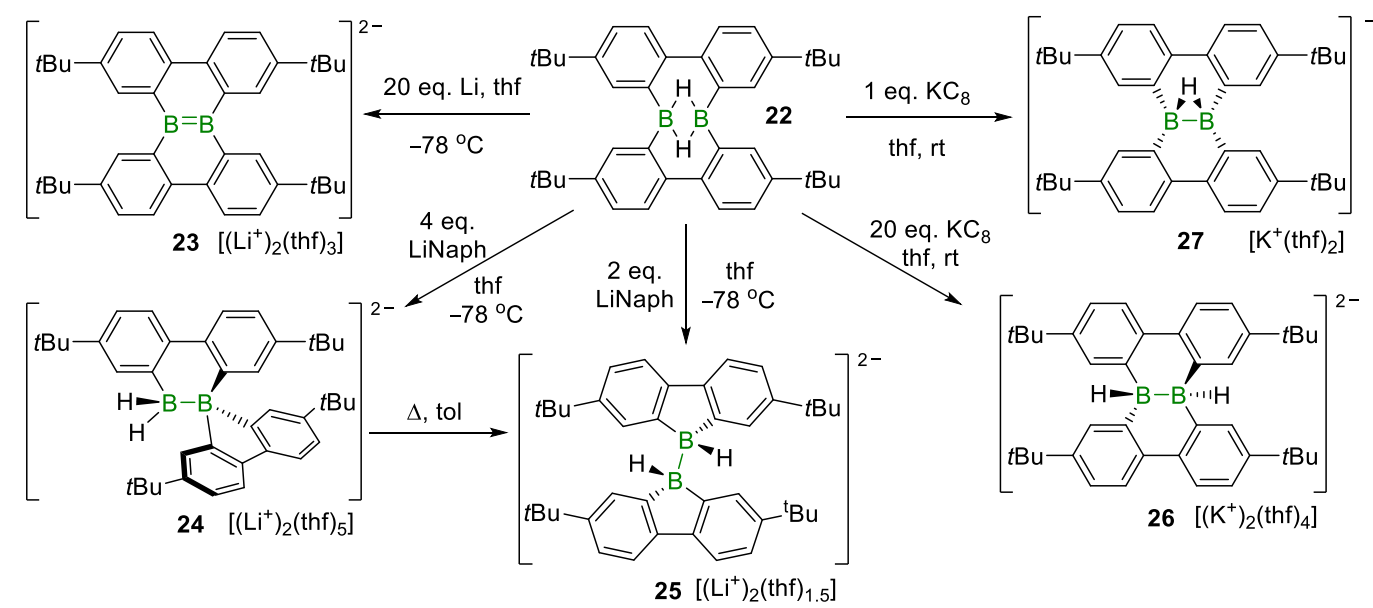

By employing bis(9-borafluorenyl) precursors in which the two borane moieties are preorganized for bond formation, the same group also accessed some radical anions presenting a rare $\mathrm{B} \bullet \mathrm{B}$ two-center-one-electron $\sigma$-bond. ${ }^{[47,48]}$ While this bonding motif between homonuclear atoms had already been observed by EPR spectroscopy, their black biphenyl-bridged bis(9-borafluorenyl) radical dianion, 29, was the first compound with a oneelectron bond to be crystallographically characterized and validated by theoretical calculations (Scheme 9). ${ }^{[4]}$ Upon reduction of 28 the B*B distance decreases from 2.920(6) to 2.265(4) $\AA$, the latter matching the calculated value of $2.262 \AA$ for 29. EPR hyperfine coupling $\left[a\left({ }^{11} \mathrm{~B}\right)=4.8{ }^{ \pm} 0.1 \mathrm{G}\right]$ and theoretical analysis of the SOMO confirmed that the spin density is essentially located in the $2 \mathrm{p}_{z} \sigma(\mathrm{B} \bullet \mathrm{B})$ orbital between the two boron atoms with no significant participation of the aryl substituents.

Scheme 9. The first crystallographically characterized compound with a B•B two-center-one-electron $\sigma$-bond.

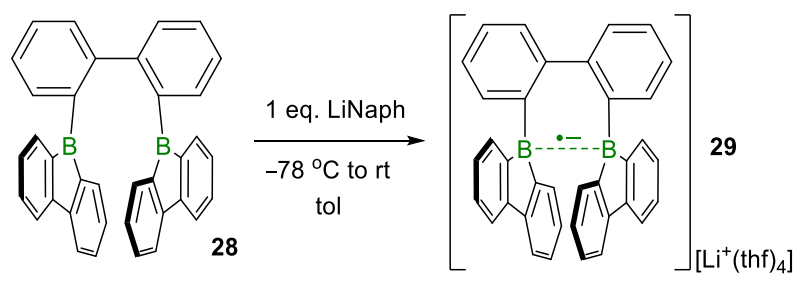

\subsection{Salt metathesis of a boryl anion and a haloboranes}

While boron is best known for its electrophilic character, there have been some advances in recent years in synthesizing stable nucleophilic boryl anions. ${ }^{[49]}$ The first example of this kind was reported in 2006 by Yamashita and Nozaki, who succeeded in reducing diamidobromoborane $\mathbf{3 0}$ with excess lithium in thf to the corresponding boryllithium, 31, 
compound presenting a B-Li bond and reacting like a nucleophile (Scheme 10). ${ }^{[50]}$ Among other reactions, compound $\mathbf{3 1}$ underwent double salt metathesis with $\mathrm{BF}_{3} \cdot \mathrm{Et}_{2} \mathrm{O}$ to yield the triborane 32, in which a central trigonal planar fluoroboryl unit is stabilized by two bulky diamidoboryl moieties. ${ }^{[51]}$ Although 32 itself was not crystallographically characterized, its chloro- and hydroxyl-derivatives, obtained by reaction of 32 with $\mathrm{Me}_{3} \mathrm{SiCl}$ and $\mathrm{LiOH}$ (or $\mathrm{SiO}_{2}$ ), respectively, could be analyzed by X-ray diffraction methods, thus confirming the formation of the triborane(5).

Scheme 10. Synthesis and B-B bond-forming reactivity of a boryl anion.

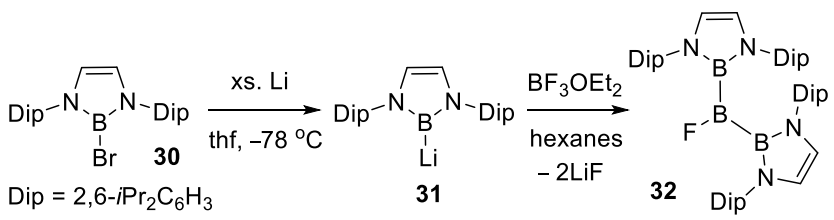

Although a number of boryl anions with nucleophilic character have since been reported, ${ }^{[52]}$ this remains the only example in which a boryl anion has been successfully used as a synthon to create new B-B bonds.

\section{Advances in the synthesis of $B=B$ double bonds}

\subsection{Early work: anionic diboron radicals and dianionic diborenes}

Unlike diborane(4), $\mathrm{B}_{2} \mathrm{H}_{4}$, the simple diborene molecule $\mathrm{B}_{2} \mathrm{H}_{2}$ has been observed by infrared spectroscopy upon photolysis of $\mathrm{B}_{2} \mathrm{H}_{6}$ at $16.8 \mathrm{eV}^{[53]}$ or reaction of pulsed-laserablated boron atoms with $\mathrm{H}_{2}{ }^{[53,54]}$ and characterized experimentally in an argon matrix by EPR and IR spectroscopy, respectively. Both theoretical calculations and experimental data point to a linear, acetylene-like $\mathrm{HBBH}$ molecule, in which one electron has been removed from each $\pi$-orbital, leading to a triplet state. ${ }^{[53-55]}$ There are, however, no examples of kinetically stable, unsupported linear diborene(2) compounds.

Early efforts took advantage of the two empty $\pi$-bonding orbitals of diborane(4) precursors to generate diboron species with higher bond orders. In 1981 Berndt and co-workers isolated the diboron radical anion 33 from the one-electron reduction of $\left[\mathrm{B}_{2} \mathrm{~Np}_{4}\right]$ (Scheme 11a). ${ }^{[56]}$ The increase in B-B bond order in such singly-reduced diboranes was later confirmed by X-ray 
crystallographic analysis in related aryl-substituted diboron radical anions by Power and coworkers. Structural data of crystals of the radical species $\left[\mathrm{Mes}_{2}(\mathrm{MeO})_{2} \mathrm{~B}_{2} \mathrm{Li}\left(\mathrm{OEt}_{2}\right)_{2}\right]^{\circ}(\mathbf{3 5})$ and $\left[(\mathrm{Mes})_{3} \mathrm{PhB}_{2}\right]^{--}(\mathbf{3 7})$ thus showed considerable shortening of the $\mathrm{B}-\mathrm{B}$ bond $[\mathbf{3 5} 1.636(7) ; 37$ 1.649(11) $\AA$ ] compared to their respective diborane(4) precursors, 34 [1.724(9) $\AA]$ and 36 $[1.706(12) \AA]$ (Scheme $11 \mathrm{~b}-\mathrm{c}) .{ }^{[57,58]}$ Furthermore, the seven-line EPR spectrum of 37 evidenced strong hyperfine coupling to both boron atoms $\left[a\left({ }^{11} \mathrm{~B}\right)=13 \mathrm{G}\right]$, indicating a significant amount of spin density located in the partial B-B $\pi$-bond. ${ }^{[58]}$

Scheme 11. One- and two-electron reductions of diborane(4) compounds.

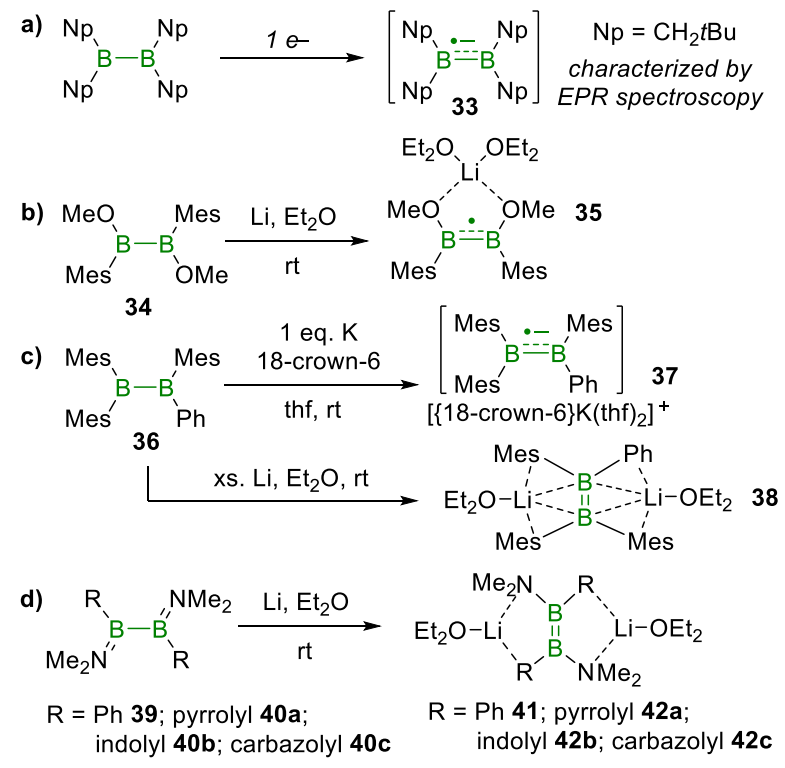

Both Power and Nöth showed that tetraaryl- (36), diamino(diaryl)- (39) and (tetraamino)diborane $(4)$ compounds $(\mathbf{4 0 a}-\mathbf{c})$ can undergo two-electron reduction to the corresponding diborate dianions (Scheme $10 \mathrm{c}-\mathrm{d}$ ). ${ }^{[59,60]}$ While the B-B bond lengths in the aryl-substituted dianions 38 and $\mathbf{4 1}$ [av. $1.63 \AA]^{[60]}$ are barely shorter than that in the radical anion 37 [1.649(11) $\AA]$, ${ }^{[58]}$ the tetraamino-substituted dianions 42a-c exhibit significantly shorter $\mathrm{B}=\mathrm{B}$ bonds [av. $1.58 \AA] .{ }^{[59]} \mathrm{NBO}$ analysis of the latter revealed a two-electron $\pi$-bond strongly localized between the two boron atoms. This was also confirmed by the considerable elongation of the B-N bonds from $40 \mathrm{a}-\mathbf{c}$ [av. $1.44 \AA$ ] to $42 \mathrm{a}-\mathbf{c}$ [av. $1.55 \AA$ ], indicating the absence of $\pi$-delocalization through the $\mathrm{B}-\mathrm{N}$ bonds.

\subsection{Neutral diborenes}

The first stable neutral diborenes, $[(\mathrm{NHC}) \mathrm{BH}]_{2}, \quad(\mathrm{NHC}=\operatorname{IDip}=1,3-$ bis $(2,6-$ diisopropylphenyl)imidazol-2-ylidene 44a; IMes = 1,3-bis(2,4,6-trimethylphenyl)imidazol-2- 
ylidene 44b) were isolated in 2007 and 2008, respectively, by Robinson and co-workers as minor products $(12-15 \%)$ of the reduction of the corresponding NHC-stabilized tribromoborane precursor $\left[(\mathrm{NHC}) \mathrm{BBr}_{3}\right] \quad(\mathrm{NHC}=\mathrm{IDip}$ 43a; IMes 43b) alongside tetrahydrodiborane(6) compounds, 45a-b (Scheme 12a). ${ }^{[61]}$ The boron-bound hydrogen atoms of diborenes $\mathbf{4 4 a - b}$ likely result from hydrogen abstraction from diethyl ether by boryl radical reduction intermediates. Diborenes 44a and 44b exhibit short B=B bonds [44a 1.561(18); 44b 1.582(4)-1.680(6) Å, depending on polymorph] and a broad ${ }^{11} \mathrm{~B}$ NMR resonance at ca. 25 ppm. In both cases, analysis of the frontier molecular orbitals shows a localized B-B $\pi$ bonding HOMO, similar to that of ethene (Figure 1), and a B-B $\sigma$-bonding HOMO-1.

In contrast, our own efforts in this area have shown that the reductive coupling of IMestabilized aryl- and heteroaryldichloroboranes (IMe = 1,3-dimethylimidazol-2-ylidene), compounds $\mathbf{4 6} \mathbf{a}-\mathbf{c}$ and $\mathbf{4 7 a}-\mathbf{b}$, proceeds rather selectively (67-89\% isolated yield) to the corresponding 1,2-(diheteroaryl)diborenes, compounds 48a-c and 49a-b (Scheme 12b). ${ }^{[62,63]}$ Similarly to the dihydrodiborene derivatives $\mathbf{4 4 a - b}$, these compounds are all intensely colored and present characteristic broad ${ }^{11} \mathrm{~B}$ NMR shifts at $18.7-24.7 \mathrm{ppm}$, as well as short $\mathrm{B}=\mathrm{B}$ double bonds [ca. $1.59 \AA$ ] in a planar trans-configuration and IMe ligands strongly twisted out of the $[>B=B<]$ plane. One notable difference between diaryldiborenes 49a-b and diheteroaryldiborenes $\mathbf{4 8 a}-\mathbf{c}$ is that the thienyl or furanyl rings in the latter lie within the $[>\mathrm{B}=\mathrm{B}<]$ plane,${ }^{[62]}$ whereas the mesityl or duryl groups are twisted out of it. ${ }^{[63]}$ This leads to enhanced $\pi$-conjugation between the heteroaromatic substituents and the $\mathrm{B}=\mathrm{B}$ bond and significantly influences reactivity (vide infra).

Scheme 12. Synthesis of neutral NHC-diborenes by reductive coupling of monoboranes.

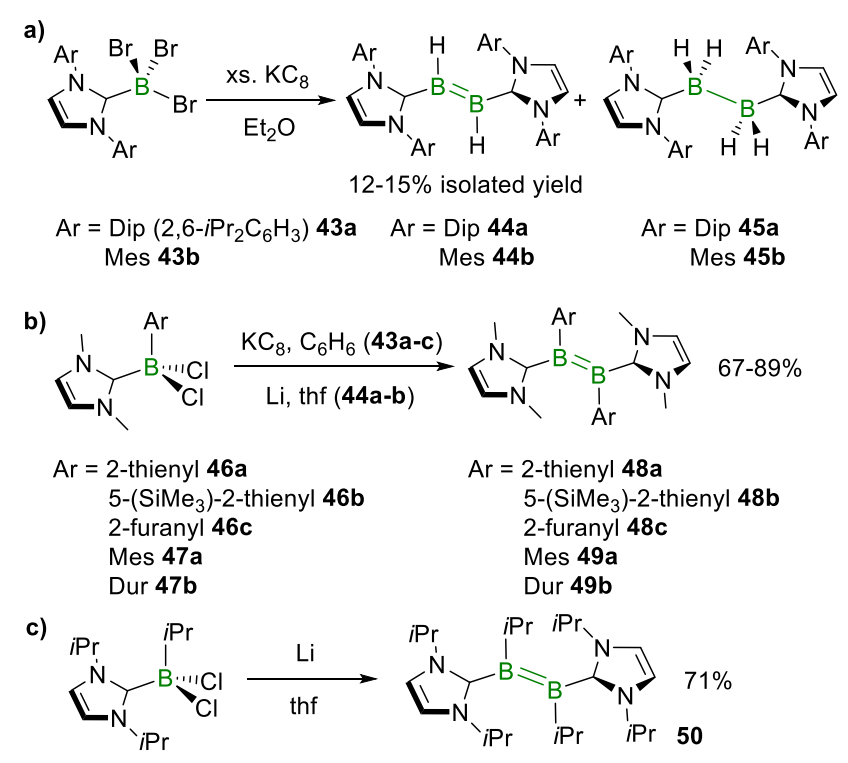


The same reductive coupling method also enabled clean access to the only reported 1,2dialkyldiborene, compound 50 (Scheme 12c). ${ }^{[64]}$ Kinetic stabilization is provided by the strongly $\sigma$-donating and sterically-demanding IiPr ligand ( $\mathrm{I} i \mathrm{Pr}=1,3$-diisopropylimidazol-2ylidene) and kinetically-stabilizing boron-bound isopropyl groups. This substitution pattern caused a significant rise in the energy of the HOMO of $\mathbf{5 0}[-2.60 \mathrm{eV}]$ compared to its 1,2dimesityl-1,2-(IMe) $)_{2}$ analogue, 49a $[-3.15 \mathrm{eV}]$, resulting in one of the most negative redox potentials observed for a neutral organic molecule $\left[E_{1 / 2}=-1.95 \mathrm{~V}\right]$. For comparison, the HOMO of ethene calculated at the same theory level is $-7.52 \mathrm{eV}$ and its HOMO-LUMO gap two to three times that of base-stabilized diborenes, depending on substitution pattern (Figure 1). It thus becomes apparent that diborenes may be far more easily reduced than alkenes.

Figure 1. Comparison of the relative HOMO-LUMO gaps (eV) of various NHC- and phosphine-stabilized diborenes with ethene optimized at the B3LYP/6-311G* level.

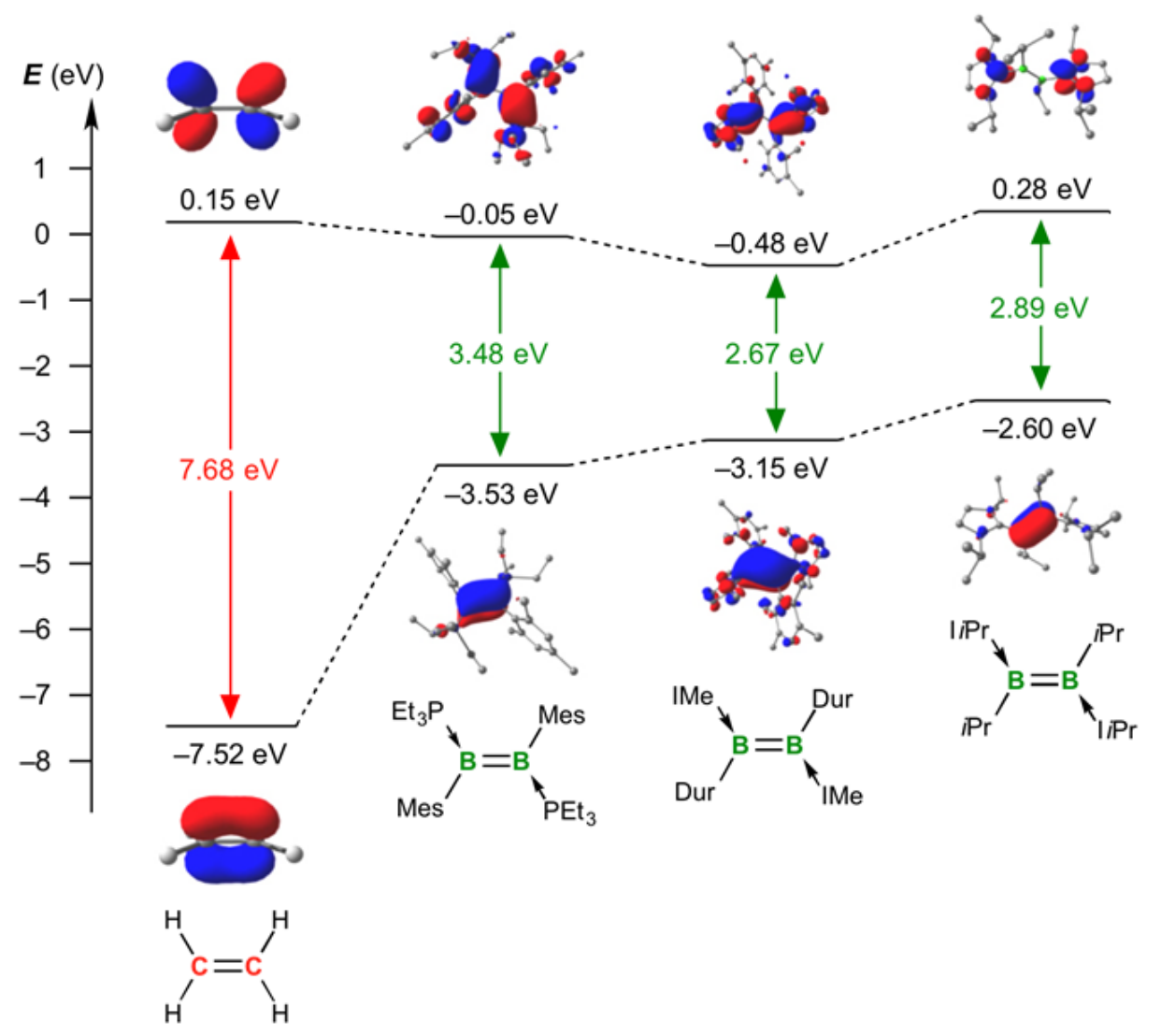

While attempts to obtain phosphine-stabilized diborenes via the reductive coupling of (dihalo)monoborane phosphine adducts were unsuccessful, these may be synthesized by reducing phosphine-supported dihalodiboranes. For trialkylphosphines $\left(\mathrm{PMe}_{3}, \mathrm{PEt}_{3}\right)$, addition to 1,2-dimesityl-1,2-dibromodiborane(4) did not lead to the 1,2-bis(phosphino) adducts but to the monophosphine bromide-bridged diboranes $\mathbf{5 1 a - b}{ }^{[65,65]}$ In the presence of a further 
equivalent of phosphine the latter could be reduced using $\mathrm{KC}_{8}$ to the corresponding 1,2bis(phosphino)-1,2-dimesityldiborenes, compounds 52a-b (Scheme 13a). ${ }^{[67,68]}$ These phosphine-stabilized diborenes display broad ${ }^{11} \mathrm{~B}$ NMR resonances around $16 \mathrm{ppm}$, slightly upfield of their NHC counterparts. Like the latter, compounds 52a-b present a planar diborene core with trans-configuration and mesityl ligands arranged quasi-orthogonally to the $[>\mathrm{B}=\mathrm{B}<$ ] plane, as well as typical $\mathrm{B}=\mathrm{B}$ double bonds [1.573(6) and 1.579(3) $\AA$, respectively]. Quantum chemical calculations showed a significant increase in the HOMO-LUMO $\left(\pi-\pi^{*}\right)$ gap of phosphine-stabilized diborenes compared to their NHC-stabilized analogues. ${ }^{[67,68]}$ This is caused on the one hand by destabilization of the LUMO and, on the other, by stabilization of the HOMO, consequences of the lower $\pi$-acceptor and $\sigma$-donor strengths, respectively, of trialkylphosphines versus NHCs (

$$
) \text {. }
$$

Scheme 13. Synthesis of neutral phosphine-stabilized diborenes by reduction of 1,2-dihalodiboranes.

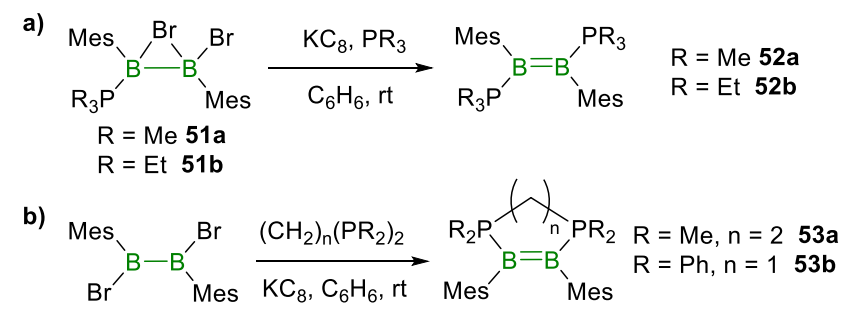

The use of chelating diphosphines also yielded the first cis-diborenes, compounds 53a and 53b, by in-situ reduction of 1,2-dibromo-1,2-dimesityldiborane(4) in the presence of 1,2bis(dimethylphosphino)ethane (dmpe) and 1,2-bis(diphenylphosphino)methane (dppm), respectively (Scheme 13b). ${ }^{[68]}$ While the dmpe derivative is yellow like the acyclic bis(phosphino) derivatives 52a-b and presents a similar ${ }^{11} \mathrm{~B}$ NMR chemical shift [18.6 ppm], the dppm derivative is red, similar to NHC-supported dihydrodiborenes $44 \mathbf{a}-\mathbf{b}^{[61]}$ and dimesityldiborenes $49 \mathbf{a}-\mathbf{b},{ }^{[63]}$ which is also reflected by a significantly deshielded ${ }^{11} \mathrm{~B}$ NMR resonance [29.3 ppm]. Computational analysis also showed a significant decrease of the HOMO-LUMO $\left(\pi-\pi^{*}\right)$ gap for 53b compared to that of 53a attributable to the strong stabilization of the LUMO by the more $\pi$-acidic dppm ligand (

). ${ }^{[68]}$ This demonstrates once more the possibility of fine-tuning the HOMO and LUMO energies, and thus the reactivity, of diborenes by a judicious choice of supporting donor ligands and/or anionic substituents (Figure 1). 


\subsection{Synthesis of metal-bound diborenes}

As mentioned above, the reaction of $\left[\left(\mathrm{Cy}_{3} \mathrm{P}\right)_{2} \mathrm{Pt}\right]$ with one equivalent of $\mathrm{DurBH}_{2}$ in boiling thf yielded, beside $\left[\left(\mathrm{Cy}_{3} \mathrm{P}\right) \mathrm{DurBH}_{2}\right]$ and $\left[\left(\mathrm{Cy}_{3} \mathrm{P}\right)_{2} \mathrm{PtH}_{2}\right]$, a few crystals of compound 16, a $\left[\left(\mathrm{Cy}_{3} \mathrm{P}\right)_{3} \mathrm{Pt}_{3}\right]$ cluster supporting a 1,2-bis(duryl)diborene moiety, resulting from the double dehydrocoupling of $\mathrm{DurBH}_{2}$ (Scheme 6). ${ }^{[42]}$ Although formally a double bond, the B-B bond in $16[1.614(6) \AA]$ is at the upper limit of B-B double bond lengths, presumably due to $\pi$ backbonding to $\mathrm{Pt}$ and $\sigma$-donation of the $\mathrm{Pt}-\mathrm{Pt}$ bond. To date, there is no reliable way to generate diborenes via the double dehydrocoupling of dihydrodiboranes.

Another approach to a non-donor-ligand-supported diborene consisted of reducing the platinum $\sigma$-diboran(4)yl complex $\mathbf{5 4}^{[69]}$ with one equivalent of the $\mathrm{Mg}^{\mathrm{I}}$ dimer $\mathbf{5 5}$, designed by Jones and co-workers (Scheme 14). ${ }^{[70]}$ The resulting $\pi$-diborene complex, 56, may be viewed as an analogue of a $\pi$-alkyne complex, but unlike the latter, which is square planar, 56 displays quasiorthogonal $\mathrm{P}-\mathrm{P}$ and $\mathrm{B}-\mathrm{B}$ axes. ${ }^{[71]}$

Scheme 14. Synthesis of a platinum $\pi$-diborene complex.

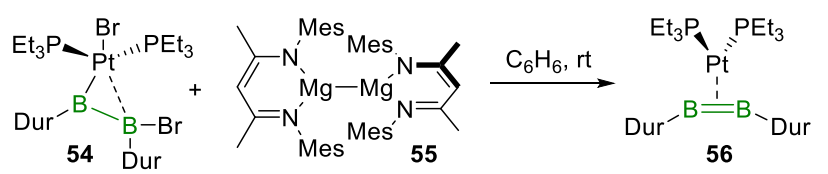

The Dewar-Chatt-Duncanson model for alkene coordination to transition metals describes $\sigma$-donation from the occupied $\pi$-bonding orbitals of the $\mathrm{C}-\mathrm{C}$ bond to the transition metal, accompanied by $\pi$-backdonation from occupied metal-based d-orbitals to the $\pi^{*}$ antibonding orbital of the alkene (

Figure 2). Both of these interactions strengthen the metal-alkene interaction at the expense of the $\mathrm{C}-\mathrm{C}$ bond strength. If the carbon atoms are replaced by boron, which has one fewer valence electron, the orbitals in the free diborene capable of accepting $\pi$-electron density from the metal are expected to be singly-occupied bonding orbitals. In principle, this allows a situation where $\pi$-backbonding could strengthen the bond between the boron atoms. Indeed, the B-B bond of $\mathbf{5 6}$ was shown both experimentally and computationally to be strengthened by backdonation from the highly electron-rich platinum center. The bent structure of the diborene when bound to platinum $\left[\mathrm{C}-\mathrm{B}-\mathrm{B} 164.2(8), 166.0(8)^{\circ}\right]$ renders the SOMOs of the 
free diborene non-degenerate, and the $\pi$-orbital orthogonal to the $\mathrm{MB}_{2}$ plane accepts electron density from Pt. Furthermore, the $\mathrm{B}=\mathrm{B}$ bond $[1.510(14) \AA]$ is even shorter than that calculated for the free diborene $\mathrm{PhB}=\mathrm{BPh}[1.52 \AA]$, which was calculated to be a linear triplet.

There are also a couple of examples of group 11 metal-bound NHC-stabilized diborenes. ${ }^{[63 \text {, }}$ ${ }^{72]}$ These will be described later in the section about the coordination chemistry of isolated diborenes (vide infra).

Figure 2. Molecular orbital interactions in Pt-alkyne versus Pt-diborene complexes.

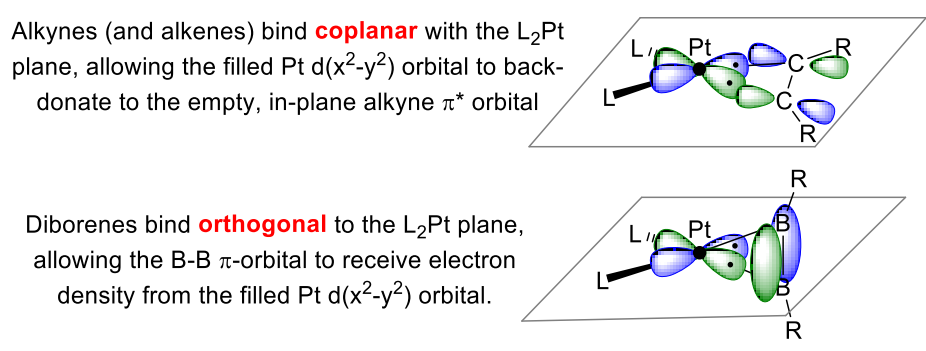


Table 3. Color, B-B distances and ${ }^{11}$ B NMR shifts in B-B multiply bonded species.

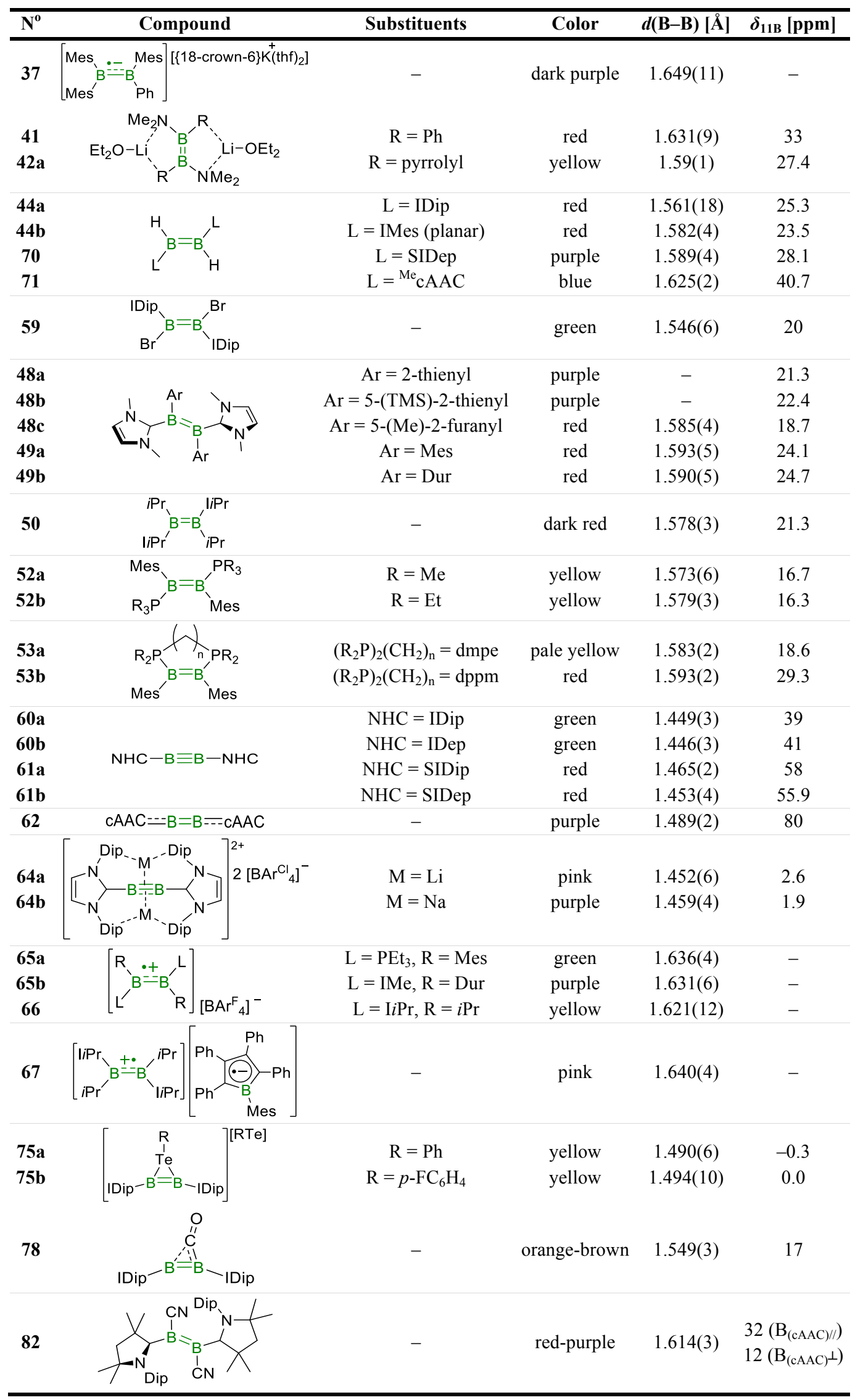




\section{Formation of $B \equiv B$ triple bonds}

\subsection{Synthesis of the first diboryne}

Despite the ubiquity of alkynes in organic chemistry, main-group homoatomic bonds with unambiguous triple bond character, consisting of one $\sigma$-bond and two $\pi$-bonds, were until recently limited to carbon (alkynes) and nitrogen $\left(\mathrm{N}_{2}\right)$. Although compounds formally containing homoatomic triple bonds are now known for several main-group elements, the heavier derivatives - both neutral $(\mathrm{Si}, \mathrm{Ge}, \mathrm{Sn}, \mathrm{Pb})^{[73]}$ and negatively charged compounds ( $\mathrm{Al}$, $\mathrm{Ga})^{[74]}$ - possess trans-bent structures containing lone-pair electron density at the bent atoms. Extension of this series to less electronegative boron has long been an alluring goal for maingroup chemists.

Initial attempts focussed on reducing aryldihaloboranes to produce an anionic diboryne of the form $[\mathrm{RB} \equiv \mathrm{BR}]^{2-}$ - a strategy which later proved successful for the heavier group 13 congeners with the isolation of $\mathrm{Na}_{2}[\mathrm{RGaGaR}]$ and $\mathrm{Na}_{2}[\mathrm{RAlAlR}] .{ }^{[26,75]}$ In the case of boron, however, this resulted in the generation of a transient borylene species, which inserted into a $\mathrm{C}-\mathrm{C}$ bond of the terphenyl substituent ( 
Scheme 2). ${ }^{[4]}$

The possibility of using neutral donor ligands to stabilize the diboryne $\mathrm{B}_{2}$ fragment was first considered by Zhou and co-workers in 2002, who synthesized [OC $\rightarrow \mathrm{B}_{2} \leftarrow \mathrm{CO}$ ] by cocondensation of boron atoms with $\mathrm{CO}$ in an argon matrix. ${ }^{[76]}$ The compound was found to be linear, and possessed some multiple bonding character according to DFT calculations. Albeit unstable at ambient temperature, this discovery allowed for some optimism that isolable variants may be accessible using appropriate stabilizing ligands. Calculations by Li and Wang subsequently predicted the stability of boronyl-substituted $[\mathrm{OBBBBO}]^{2-}$, with a Wiberg Bond Index of 2.43 for the central B-B moiety, indicating considerable triple-bond character. ${ }^{[77]}$ Further high-level DFT calculations by the groups of Mavridis ${ }^{[78]}$ and Frenking ${ }^{[79]}$ also predicted compounds of the form $\left[\mathrm{L} \rightarrow \mathrm{B}_{2} \leftarrow \mathrm{L}\right]\left(\mathrm{L}=\mathrm{CO}, \mathrm{CS}, \mathrm{N}_{2}, \mathrm{BO}^{-}\right.$, noble gases) to be stable, linear molecules with boron-boron triple bonds. The groups of Mitoraj ${ }^{[80]}$ and Frenking ${ }^{[81]}$ also considered ligands such as phosphines and NHCs as support for the $\mathrm{B}_{2}$ unit, again confirming the linear structure, and finding short B-B distances [1.46 $\AA$ ].

With the theoretical groundwork laid, it remained to develop a synthetic route to a diboryne. It had been previously reported by Robinson that reduction of [(NHC)BBr 3 leads predominantly to hydrogen atom abstraction from solvent molecules rather than diboryne formation, ${ }^{[66]}$ likely due to a slow B-B coupling step (vide supra). Our group circumvented this step by using a compound with a pre-formed boron-boron bond. ${ }^{[82]}$ Addition of IDip to tetrabromodiborane(4) (57) yielded the stable adduct [IDip $\rightarrow \mathrm{B}_{2} \mathrm{Br}_{4} \leftarrow$ IDip] (58) which could be reduced with four equivalents of sodium naphthalenide to provide the first diboryne stable at ambient temperature, [IDip $\rightarrow \mathrm{B} \equiv \mathrm{B} \leftarrow$ IDip], 60a , in 57\% yield (Scheme 15). Compound 60a displayed the shortest measured B-B bond length to date, at 1.449(3) $\AA$, similar to those predicted theoretically, and was found to be remarkably thermally stable, decomposing only at $234{ }^{\circ} \mathrm{C}$. The $\mathrm{C}-\mathrm{B} \equiv \mathrm{B}-\mathrm{C}$ core of the molecule is close to linear $\left[\mathrm{B}-\mathrm{B}-\mathrm{C} 173.0(2)^{\circ}\right.$, $\left.173.3(2)^{\circ}\right]$, in stark contrast to the heavily trans-bent structures of previously reported dianionic dialumyne and digallyne compounds, indicating significant triple bond character. Reaction of $\mathbf{5 8}$ with two equivalents of reducing agent led to the isolation of 1,2dibromodiborene 59, a compound that could also be accessed via a comproportionation reaction of diborane 58 and diboryne $\mathbf{6 0 a}$. 


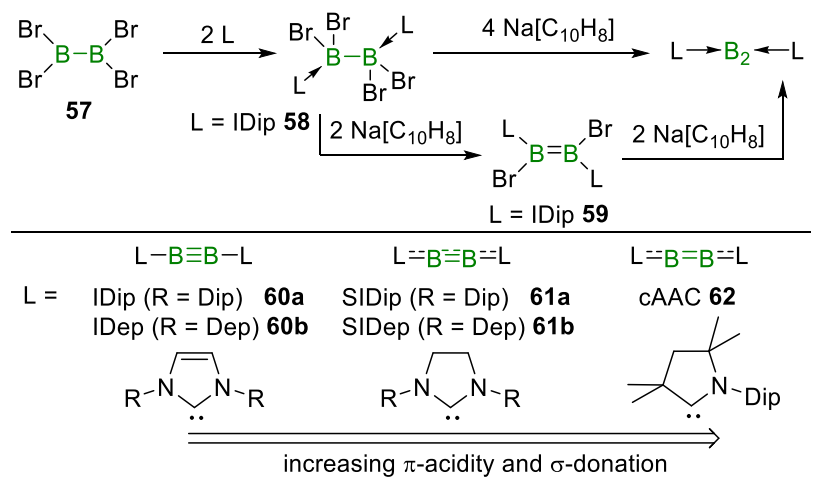

\subsection{Controversy}

Schnöckel and Köppe criticized the assignment of a triple bond in the above diboryne compounds on the basis of thermodynamic considerations, ${ }^{[83]}$ centering on the assertion that the vastly lower energy of compound 60a relative to the ${ }^{1} \Sigma$ singlet excited state of free $\mathrm{B}_{2}$ and two NHC ligands could only be explained on the basis of a dramatic change in the bonding situation - in other words, implying $\mathrm{C}-\mathrm{B}$ bonds with significant multiple bond character rather than dative bonds from the carbenes. They also argued that force constants calculated for a simplified derivative of 60a did not support the existence of a triple bond, instead advocating a 4-center-4-electron $\pi$-bond spread over the C-B-B-C framework. The methods used in this analysis have attracted heavy criticism from others in the field, ${ }^{[84]}$ whose results support the original triple bond assignment. Further experimental data were also obtained, reaching a similar conclusion: a subsequent Raman spectroscopic study on compound 60a found the B-B stretching frequency to fit well into the trend already established for $\mathrm{C} \equiv \mathrm{C}$ and $\mathrm{N} \equiv \mathrm{N}$ triple bonds. Furthermore, measurement of the $J\left({ }^{11} \mathrm{~B}-{ }^{11} \mathrm{~B}\right)$ coupling constants by NMR spectroscopy, a parameter determined by the hybridization of the atoms and the s-character of the bond, ${ }^{[85]}$ also provided values consistent with a triple-bond in $\mathbf{6 0 a} .{ }^{[86]}$

The Braunschweig group subsequently explored the effects of modifying the carbene ligand in diborynes. Of the plethora of carbenes now accessible, ${ }^{[87]}$ the cyclic(alkyl)(amino)carbenes (cAAC) pioneered by Bertrand and co-workers are particularly noteworthy due to their considerably stronger $\pi$-acceptor strength compared to NHCs. ${ }^{[88]}$ Analogously to the synthesis of $\mathbf{6 0 a}$, reduction of the cAAC adduct of $\mathbf{5 7}$ with $\mathrm{Na}\left[\mathrm{C}_{8} \mathrm{H}_{10}\right]$ led to the species $\left[\mathrm{B}_{2}(\mathrm{cAAC})_{2}\right](\mathbf{6 2}$; Scheme 15$) .{ }^{[89]}$ Rather than a diboryne, this compound is better described as a diboracumulene. The longer B-B [1.489(2) $\AA$ ] and shorter $\mathrm{B}-\mathrm{C}$ $[1.458(2), 1.459(2) \AA]$ bond distances indicate delocalization of the electron density over the B-C units, while DFT calculations and UV-vis data also support this assignment. A further 
study employed an NHC with a saturated hydrocarbon backbone (SIDip, Scheme 15), known to be more $\pi$-acidic than unsaturated NHCs but less so than cAAC ligands. ${ }^{\left[{ }^{90]}\right.}$ This resulted in diboron species 61a with crystallographically-determined bond lengths intermediate between the diboryne and diboracumulene extremes [B-B 1.465(2); B-C 1.480(2), 1.482(2) $\AA$ ]. This trend was also neatly displayed by the divergent reactivity of the three $\left[\mathrm{L} \rightarrow \mathrm{B}_{2} \leftarrow \mathrm{L}\right]$ compounds towards carbon monoxide as discussed below. ${ }^{[91]}$ In an attempt to find a compromise between kinetic stability and high reactivity towards substrates, less sterically hindered diborynes supported by IDep and SIDep, compounds 60b and 61b, respectively, have also been prepared in an analogous fashion (vide infra). ${ }^{[92]}$ The steric protection of the substituents evidently plays a significant role in the stability of diborynes, but the picture may be more complex than first thought, with recent computational work suggesting a large contribution of dispersion interactions to the stability of carbene-stabilized main-group compounds. ${ }^{[93]}$

\section{Reactivity of BB Multiple Bonds}

As the subject of B-B single bond reactivity - in particular reactions of diborane(4) compounds - has been recently reviewed, ${ }^{[1]}$ this section will focus exclusively on the more recent advances in B-B multiple bond reactivity, an area which is just beginning to emerge.

\subsection{General considerations}

Whereas boranes are best known for their Lewis acidic properties, low oxidation state boron species are electron-rich and display some Lewis basic and reducing character. Thus Bertrand and co-workers showed that a bis(cAAC)-supported hydroborylene, displaying a formally boron(I) center, reacts as a base towards triflic acid and may be oxidized by $\mathrm{GaCl}_{3}$ to the corresponding radical cation. ${ }^{[94]}$ Furthermore, Kinjo and co-workers isolated a bis(oxazol2-ylidene)-stabilized phenylborylene, the nucleophilic character of which was confirmed by reaction with triflic acid and formation of a chromium borylene complex upon reaction with $\left[(\operatorname{thf}) \mathrm{Cr}(\mathrm{CO})_{5}\right] \cdot{ }^{[95]}$ In both cases, DFT calculations and analysis of frontier molecular orbitals revealed significant electron density localized on the boron center. ${ }^{[94,95]}$

Similarly, theoretical calculations on diborenes have shown that the HOMO is entirely localized in the $\pi$-bond between the two boron atoms, making the $\mathrm{B}=\mathrm{B}$ bond nucleophilic. For carbene-stabilized $\left[\mathrm{L} \rightarrow \mathrm{B}_{2} \leftarrow \mathrm{L}\right]$ species the HOMO and HOMO-1 may either be fully 
localized in the $\pi$-system of the triple bond as in the unsaturated NHC-supported diborynes, 50a and 50b,${ }^{[82,88]}$ partially delocalized over the $\mathrm{C}-\mathrm{B}-\mathrm{B}-\mathrm{C}$ framework as in the saturated NHC-supported species $\mathbf{5 1 a}$ and $\mathbf{5 1 b},{ }^{[90,96]}$ or fully delocalized over the C-B-B-C framework as in diboracumulene 52, which displays strong $\pi$-backbonding to the flanking cAAC ligands. ${ }^{[89]}$ The reactivity of $\left[\mathrm{L} \rightarrow \mathrm{B}_{2} \leftarrow \mathrm{L}\right]$ species is therefore expected to strongly vary depending on the electronic nature of the supporting carbene ligand.

\subsection{Coordination chemistry}

The coordination of carbon-carbon $\pi$-bonds to metals represents one of the fundamental pillars of organometallic chemistry, forming the basis for countless vital processes for the functionalization and polymerization of organic molecules. As base-stabilized diborenes and diborynes are isolobal to alkenes and alkynes, respectively, the coordination of boron-boron bonds to metals is likely to be beneficial for the incorporation of boron into new compounds and materials. Metal coordination also offers an opportunity to modify the interesting optical properties observed in multiply-bonded boron species.

The first example of diborene coordination to a metal was published by our group in 2012. ${ }^{[63]}$ The IMe-stabilized bis(duryl)diborene 49b was shown to react with $\mathrm{AgCl}$ at room temperature to afford a side-on coordinated silver complex, compound 63a (Scheme 16a). Coordination of the silver fragment produced a slight increase in the B-B bond length [63a 1.645(6), 49b 1.590(5) $\AA$ ], while the diborene unit remained essentially planar, indicating only weak interaction with the metal. In stark contrast to alkene complexes of the same metals, this silver complex and its copper analogue, $\mathbf{6 3} \mathbf{b}$, were also found to be highly luminescent, with unusually high fluorescence quantum yields approaching $100 \%$. ${ }^{\text {[2] }}$

Scheme 16. Coordination chemistry of carbene-stabilized diborenes and diborynes.

a)
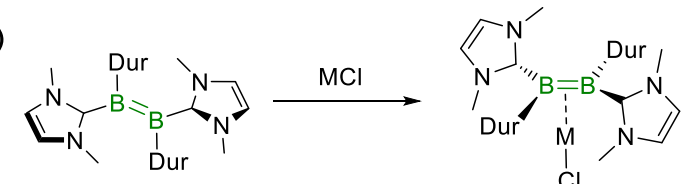

$49 b$

$M=\operatorname{Ag~63a,~Cu~63b~}$

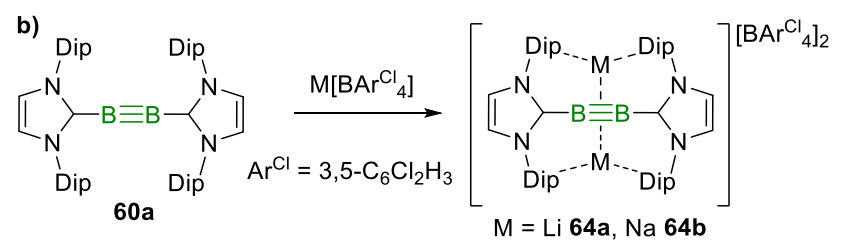


Diboryne 60a proved capable of capturing the light alkali metal cations $\mathrm{Li}^{+}$and $\mathrm{Na}^{+}-\mathrm{a}$ rare property for a neutral molecule. ${ }^{[97]}$ Reaction of $\mathrm{M}\left[\mathrm{B}\left(3,5-\mathrm{C}_{6} \mathrm{Cl}_{2} \mathrm{H}_{3}\right)_{4}\right]$ with $\mathbf{6 0 a}$ resulted in the coordination of first one, then two alkali metal cations to the triple bond, eventually yielding the dications 64a and 64b (Scheme 16b) The crystallographically-determined B-B bond lengths of the new dications [64a 1.452(6), 64b 1.459(4) $\AA$ )] were comparable to that of 60a $[1.449(3) \AA]$, indicating the lack of any significant covalent $\mathrm{Li}-\mathrm{B}$ bonding character.

At present, the coordination chemistry of boron-boron multiple bonds is somewhat limited by the bulky ligands necessary for their stabilization. New strategies to reliably produce less sterically encumbered multiply bonded species would likely pave the way for a rapid expansion of this nascent field.

\subsection{Redox Chemistry}

Due to the high electron density at a relatively electropositive element, diborenes act as strong reducing agents. Cyclic voltammetric measurements performed on NHC- and phosphine-stabilized diborenes, 49b and 52b, respectively, showed the occurrence of oxidation events at highly negative potentials [49b 1.55 and $0.51 \mathrm{~V} ; \mathbf{5 2 b} 1.05 \mathrm{~V}] .{ }^{[67]}$ These values represent some of the strongest reduction potentials for neutral molecules. The significant disparity between the NHC- and phosphine-stabilized species reflects the substantially stronger electron-donating properties of the NHC, which causes an increase in the energy of the HOMO (Figure 1). By contrast, the oxidation of the dppm-stabilized cisdiborene 53b occurs at much higher potential $\left[\mathrm{E}_{1 / 2}=-0.51 \mathrm{~V}\right]$, implying a considerably less electron-rich system. ${ }^{[64]}$ The chemical oxidation of $49 \mathrm{~b}$ and $\mathbf{5 2 b}$ with the weak oxidising agent $\left[\mathrm{C}_{7} \mathrm{H}_{7}\right]\left[\mathrm{BAr}_{4}^{\mathrm{F}}\right]$ led to the isolation of boron-centred radical cations $\mathbf{6 5 a}$ and $\mathbf{6 5 \mathbf { b }}$ (Scheme 17a). The B-B bond lengths of the oxidized products [65a 1.636(4); 65b 1.631(6) $\AA$ ] are somewhat lengthened compared to their neutral precursors [49b 1.590(5); 52b 1.579(3) $\AA$ ], consistent with a reduction of the formal B-B bond order from 2 to 1.5. The even more strongly-reducing diisopropyldiborene $\mathbf{5 0}\left[\mathrm{E}_{1 / 2}=-1.95 \mathrm{~V}\right]$ was subsequently prepared, with electron-donating isopropyl substituents at boron. ${ }^{[64]}$ As well as being oxidized by $\left[\mathrm{C}_{7} \mathrm{H}_{7}\right]\left[\mathrm{BAr}_{4}^{\mathrm{F}}\right]$, providing the radical cation salt 66, compound 50 also proved to be a powerful enough reductant to reduce the borole $\mathrm{MesBC}_{4} \mathrm{Ph}_{4}\left[\mathrm{E}_{1 / 2}=-1.69 \mathrm{~V}\right]$, forming the first example of a fully boron-centered radical-cation-radical-anion pair, compound 67 (Scheme $17 b)$. 
a)

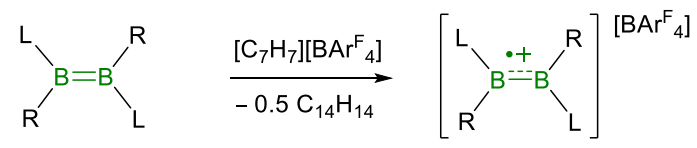

$L=I M e, R=$ Dur $65 a$

$L=P E t_{3}, R=$ Mes 65b

$L=I i P r, R=i P r \quad 66$

b) $\underbrace{i \mathrm{Pr}}_{i \mathrm{Pr}}$

\subsection{Reactions with elemental chalcogens}

While exposure to oxygen typically leads to rapid and uncontrolled decomposition of multiply-bonded boron species, examples have emerged of the heavier chalcogens undergoing oxidative insertion into B-B multiple bonds. As early as 1999, Tokitoh and co-workers reported a photolytic reaction of the bulky borane [(Tbt)B(SeMe $\left.)_{2}\right](\mathrm{Tbt}=2,4,6-$ tris[bis(trimethylsilyl)methyl]phenyl), producing a triselenadiboralane heterocycle, purportedly via a diborene intermediate (Scheme 18a). ${ }^{[93]}$ The same reaction in the presence of dimethyldisulfide provided the corresponding trisulfadiboralane. The plausibility of this mechanism was recently established by our group, by obtaining a related 5-membered heterocycle, compound $\mathbf{6 5}$, by the insertion of elemental sulfur into isolated diborene $\mathbf{4 8 b}$, which represents a four-electron oxidation of the diborene fragment (Scheme 18b). ${ }^{[97]}$

Reaction of diborene 48a with excess Se or Te also resulted in reduction of the chalcogen, although conversely, in this case the products, 69a and 69b, contained strained, threemembered $\mathrm{B}_{2} \mathrm{E}$ heterocycles (Scheme 18c). ${ }^{[98]}$ The B-B bonds were lengthened with respect to the diborene starting materials, but nonetheless shorter than typical single bonds in basestabilized diboranes [69a 1.707(3) $\AA$; 69b 1.713(5) $\AA$ ], following the pattern observed for related carbon $\mathrm{C}_{2} \mathrm{E}$ analogues such as thiiranes. The fact that these compounds are stable, whereas none of the few reported carbon-based seleniranes has been structurally characterized and telluriranes are unknown, is ascribed to the lower electronegativity of boron and the higher reducing power of diborenes as compared to alkenes.

Diboryne 60a was also found to react with sulfur and selenium, this time affording [2.2.1]bicyclic systems, 70a and 70b, via a six-electron process involving the insertion of five chalcogen atoms into the $\mathrm{B} \equiv \mathrm{B}$ triple bond, which was completely cleaved during the reaction (Scheme 18d). The equivalent reaction with elemental tellurium proved unselective. ${ }^{\text {[99] }}$ 

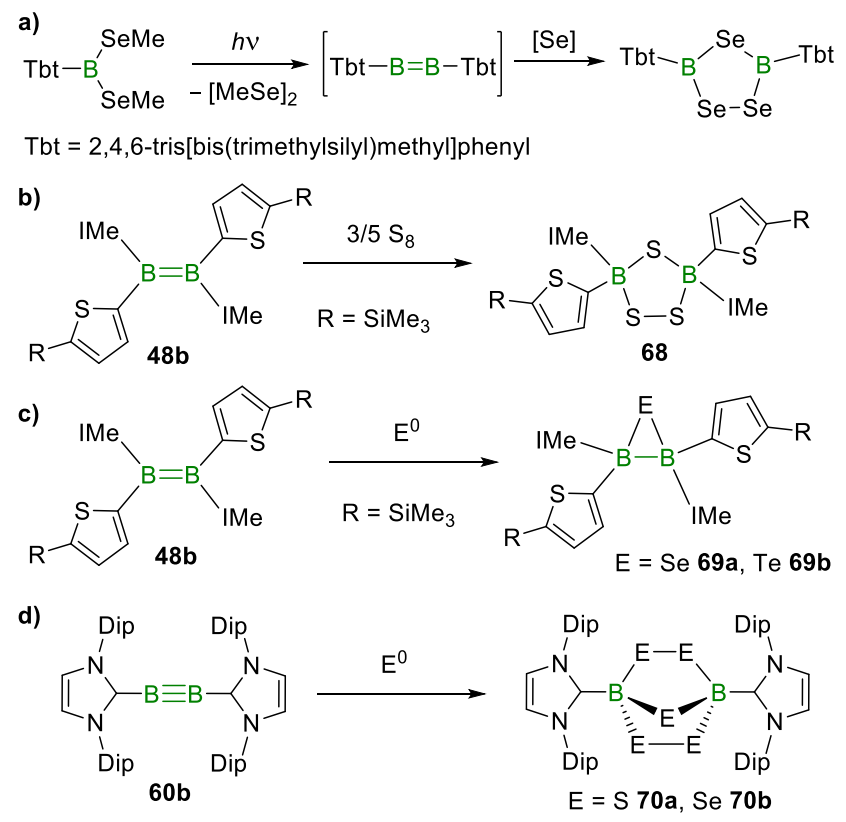

\subsection{Addition of $\sigma$-bonds}

Hydroboration. The addition of E-H bonds across unsaturated carbon-carbon multiple bonds, notable examples of which include hydroboration, hydroamination and hydrogenation, is hugely important for the functionalization of organic molecules. ${ }^{[100]}$ The extension of this chemistry to multiply-bonded boron species has the potential to provide access to a variety of more complex boron-containing molecules. With this goal in mind, we recently achieved the first hydroboration of a $\mathrm{B}=\mathrm{B}$ double bond. ${ }^{[62]}$ Room-temperature reaction of the bis(heteroaryl)diborenes $\mathbf{4 8 b}$ and $\mathbf{4 8 c}$ with catecholborane led to clean B-H addition across the $\mathrm{B}=\mathrm{B}$ bond (Scheme 19). The resulting linear triboranes, compounds 71a and 71b, display two $\mathrm{sp}^{3}$-hybridized boron atoms, whereas the catechol-substituted borane retains trigonal geometry. Formation of an electron-precise $\mathrm{B}_{3}$ chain is particularly notable given the high propensity of boron species to form clusters, and indeed use of a different hydroboration reagent showed that in some cases, cluster formation is possible. Thus, reaction of the dithienyldiborenes $48 \mathrm{a}$ and $\mathbf{4 8 b}$ with 9-BBN led to $\mathrm{B}-\mathrm{H}$ addition across the $\mathrm{B}=\mathrm{B}$ bond concomitant with abstraction of one thienyl residue by a second 9-BBN molecule, resulting in the arachno-type $\mathrm{B}_{3} \mathrm{H}_{2}$ clusters $\mathbf{7 2} \mathbf{a}$ and $\mathbf{7 2} \mathbf{b}$, alongside the corresponding thienylborane byproducts (Scheme 19). ${ }^{[91]}$ This divergent reactivity was tentatively assigned to the lack of electronic stabilization at the trigonal 9-BBN fragment after the initial hydroboration step, prompting the formation of multicenter bonds. 


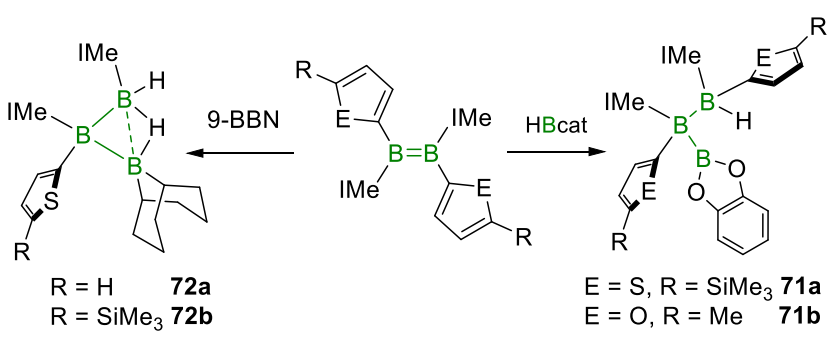

Hydrogenation. Despite the fact that the stability of 1,2-dihydrodiborenes, such as 44a and 44b, had been demonstrated by Robinson and co-workers (vide supra), the preparation of these potentially useful compounds from the reductive coupling of [(IDip)BBr 3 ] was unselective and low-yielding. ${ }^{[61]}$ The selective preparation of such compounds was subsequently attempted by the direct reaction of diborynes with $\mathrm{H}_{2} \cdot{ }^{[96]}$ Of the five diborynes and diboracumulenes reported to date, analogues bearing unsaturated NHCs, compounds 60a and 60b, as well as the saturated SIDip analogue 61a, showed no reactivity towards $\mathrm{H}_{2}$ (Scheme 20a), whereas the SIDep-supported diboryne $\mathbf{6 1 b}$ and the cAAC-supported diboracumulene 62 could be hydrogenated to the corresponding planar trans-1,2dihydrodiborenes, compounds $\mathbf{7 3}$ and 74, respectively (Scheme 20b,c). Interestingly, the propensity to undergo hydrogenation seemed to increase with increasing $\pi$-acceptor character of the supporting carbene ligands, while the reduced steric demands of the SIDep ligand allow increased reactivity compared to SIDip. As expected, the B=B bond of 73 [1.589(4) $\AA$ ] is slightly longer than that of IDip-stabilized $\mathbf{4 4 a},{ }^{[61]}$ while that of $\mathbf{7 4}[1.625(2) \AA]$ is further elongated, as in other cAAC derivatives, due to $\pi$-backbonding from the diborene to the cAAC ligands. DFT calculation revealed a reaction mechanism analogous to that calculated for the hydrogenation of amido-substituted ditetrylynes, ${ }^{[101]}$ with initial binding of $\mathrm{H}_{2}$ at one boron center, followed by $\mathrm{H}-\mathrm{H}$ cleavage via a bridging hydride intermediate.

Scheme 20. Hydrogenation reactivity of $\left[\mathrm{LB}_{2} \mathrm{~L}\right]$ species.

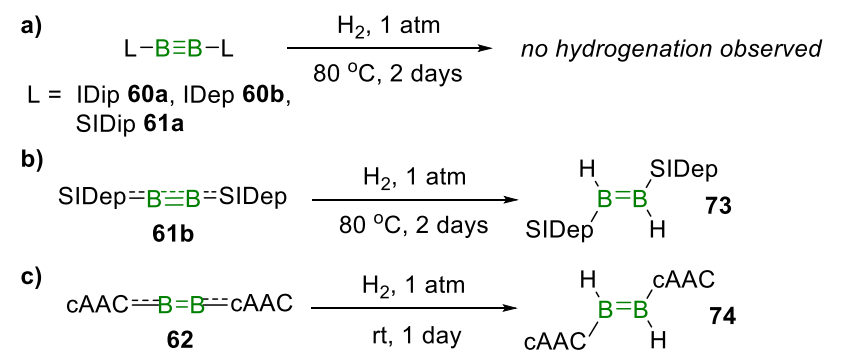

Ditelluride addition. Diboryne 60a induced heterolytic cleavage of ditellurides, RTeTeR (R $\left.=\mathrm{Ph}, 4-\mathrm{C}_{6} \mathrm{H}_{4} \mathrm{~F}\right) \cdot{ }^{[98]} \mathrm{A}$ proposed nucleophilic attack of the $\mathrm{B} \equiv \mathrm{B}$ unit at one tellurium atom was found to yield ionic species containing a cationic, three-membered diboraphenyltellurirenium 
moiety with an aryltelluride counterion (75a,b; Scheme 21). Formally, this reaction may be viewed as an anion exchange in which a cationic telluryl moiety exchanges $\mathrm{Te}-\mathrm{Te}$ bonding to an anionic telluride moiety for two Te-B bonds to an anionic diborenide, emphasizing the nucleophilic character of the $\mathrm{B} \equiv \mathrm{B}$ triple bond. Again, the $\mathrm{B}-\mathrm{B}$ bonds [75a 1.490(6); 75b 1.494(10) $\AA$ ] are somewhat lengthened compared to those in the diboryne precursor [60a $1.449(3) \AA],{ }^{[82]}$ but significantly shorter than that of a diborene.

Scheme 21. Addition of ditellurides to a diboryne.

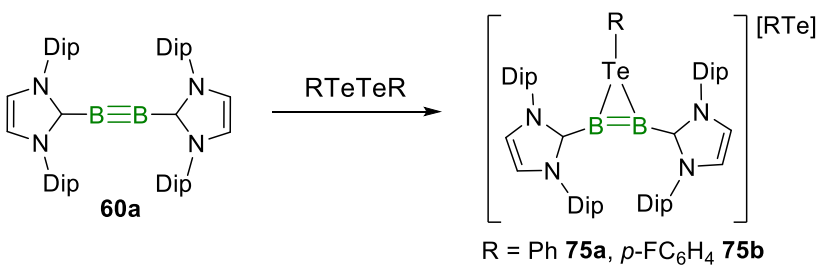

\subsection{Reactions with apolar and polar triple bonds}

Alkyne cycloaddition. Cycloaddition reactions of alkynes are a convenient route to a variety of compounds, most notably benzene derivatives. ${ }^{[102]}$ Attempting to emulate this type of reactivity with boron, we recently reported cycloadditions of B-B multiply bonded species to form carbon-boron heterocycles. ${ }^{[103]}$ Under photolytic conditions, phosphine-stabilized diborene 51a reacted with 2-butyne with complete cleavage of the $\mathrm{C} \equiv \mathrm{C}$ and $\mathrm{B}=\mathrm{B}$ bonds and migration of the phosphine to a carbon atom, to form an unusual, $2 \pi$-homoaromatic 1,3dihydro-1,3-diborete, compound 75 (Scheme 22a). Interestingly, NHC-stabilized diborenes were found to be inert towards alkynes under the same conditions. The higher reactivity of 51a was ascribed to the ability of $\mathrm{PMe}_{3}$ to dissociate under photolytic conditions to facilitate the addition of the alkyne moiety. Diboracumulene $\mathbf{6 2}$ reacted with propyne in a somewhat similar fashion to yield a 1,3-diborete flanked by cAAC ligands, compound 76 (Scheme 22b). EPR studies enabled the assignment of this compound as a triplet biradical, with the unpaired electrons located on the cAAC fragments. Apparently the formation of the puckered BCBC $2 \pi$-aromatic system is sufficient to stabilize this biradical species. Surprisingly, reaction of 62 with acetylene rather than propyne did not produce an analogous 1,3-diborete, instead resulting in a formal [2+2+2]-cycloaddition of two acetylene molecules to yield the cAACstabilized 1,4-diborabenzene, 77 (Scheme 22b). DFT calculations on 77, which is the first example of a neutral diborabenzene species, revealed frontier orbitals of remarkably similar form to those of benzene itself. 
Scheme 22. Cycloaddition reactions of alkynes with boron-boron multiply-bonded species.
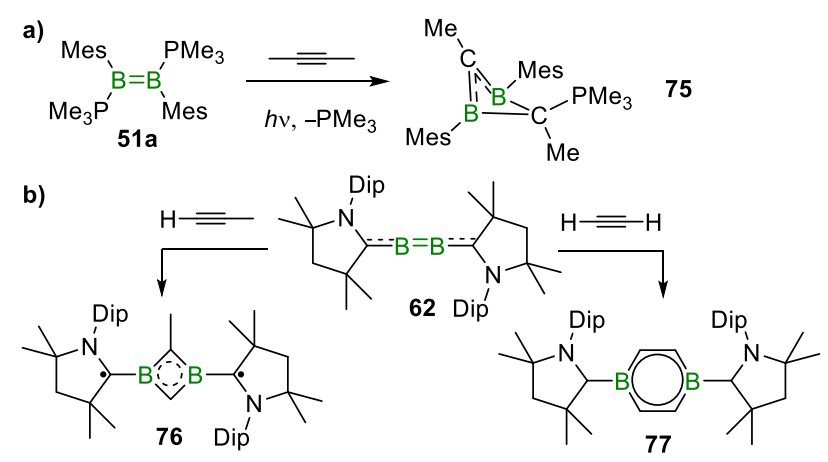

CO addition. Despite previously being almost solely a facet of transition metal chemistry, the coupling of carbon monoxide molecules was recently reported for diboron compounds. ${ }^{[104]}$ Treatment of diboryne 60a with excess $\mathrm{CO}$ at room temperature resulted in the selective formation of planar, bicyclic bis(boralactone), compound 79a (Scheme 22a). The compound is best described as a NHC-supported 1,4-dibora-1,3-butadiene, with the crystallographic bond lengths suggesting some electron delocalization throughout the system. Controlled addition of stoichiometric quantities of $\mathrm{CO}$ at low temperature allowed the isolation of a reaction intermediate, $\mathbf{7 8}$, in which a single $\mathrm{CO}$ molecule bridges the $\mathrm{B}-\mathrm{B}$ unit, the bond length of which suggests the presence of a B=B double bond [1.549(3) $\AA$ ] (Scheme 23a). Extension of this chemistry provided a further example of the profound influence of the $\pi$ acidity of the stabilizing carbene on the reactivity of the B-B bond. ${ }^{[90]}$ Diboryne 61a, supported by saturated NHC ligands, reacts with CO to initially form bis(boraketene) 77a, while further treatment with CO results in conversion to the bis(boralactone) $\mathbf{7 9 b}$, albeit much more slowly than in the IDip case (Scheme 23b). The cAAC-stabilized diboracumulene 62 can also be converted into the corresponding bis(boraketene), 80b, which presents a B-B single bond [1.744(2) $\AA$ ] (Scheme 23c). In contrast to 80a, however, no further reaction with $\mathrm{CO}$ was observed, even under forcing conditions (50 bar $\left.\mathrm{CO}, 150{ }^{\circ} \mathrm{C}\right)$. In a similar fashion, $\mathrm{CO}$ coordination to boron had already been observed for other electron-rich borylene species. ${ }^{[105]}$ 

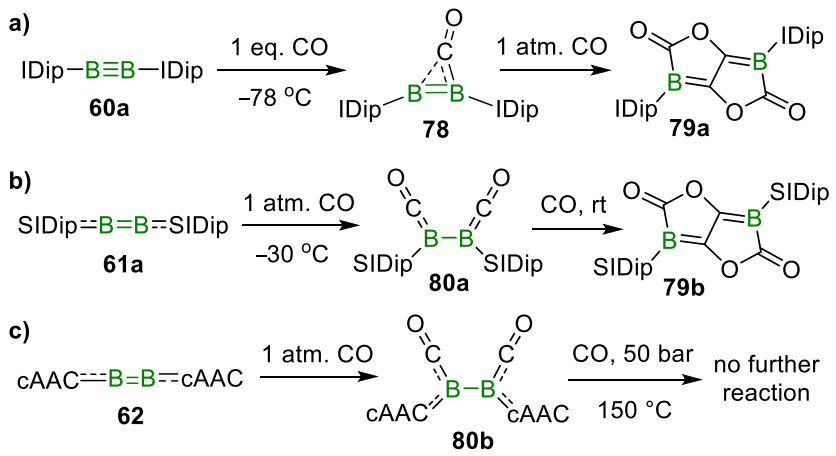

Isonitrile addition. Analogously, diboracumulene $\mathbf{6 2}$ reacts with tert-butylisocyanide to produce bis(boraketenimine) 81 (Scheme 24). ${ }^{[106]}$ The B-B bond length of 1.760(4) $\AA$ is comparable to that of the bis(CO) adduct, 80b, and befitting a $\mathrm{B}-\mathrm{B}$ single bond. The respective $\mathrm{C}-\mathrm{O}$ and $\mathrm{C}-\mathrm{N}$ stretching frequencies, as measured by IR spectroscopy, both indicate a degree of backdonation from boron comparable to that typically found in transition metal complexes. Compound $\mathbf{8 1}$ decomposes at $110{ }^{\circ} \mathrm{C}$ in xylene with loss of two isobutyl radicals, which react to form isobutene and isobutane, leaving 1,2-dicyanodiborene 82 as the boron-containing product [B-B 1.614(3) $\AA$ ]. This reactivity has precedent in work by Sekiguchi with disilicon compounds. ${ }^{[107]}$ Interestingly, compound 79 displays two distinct boron NMR resonances [32 and $12 \mathrm{ppm}$ ], which reflects the structural dissymmetry also observed by X-ray crystallographic analysis. Whereas the $\pi$-framework of one of the cAAC ligands is coplanar and conjugated with the dicyanodiborene core [B-C// 1.530(3) $\AA$ ], the other is positioned perpendicular to the dicyanodiborene core and presents a longer $\mathrm{B}-\mathrm{C} \perp$ bond [1.595(3) $\AA$ ]. Coalescence of the two ${ }^{11} \mathrm{~B}$ NMR resonances [24 ppm] was observed at 60 ${ }^{\circ} \mathrm{C}$, which corresponds to a barrier of rotation about the $\mathrm{B}-\mathrm{C}_{\mathrm{cAAC}}$ bond of $13.7 \mathrm{kcal} \cdot \mathrm{mol}^{-1}$. Cyclic voltammetry showed $\mathbf{8 2}$ to be the most electron-poor diborene yet reported, as evidenced by two reduction waves at $-2.20 \mathrm{~V}$ and $-2.25 \mathrm{~V}$.

Scheme 24. Reaction of a diboracumulene with tert-butylisonitrile and thermolysis of the product.

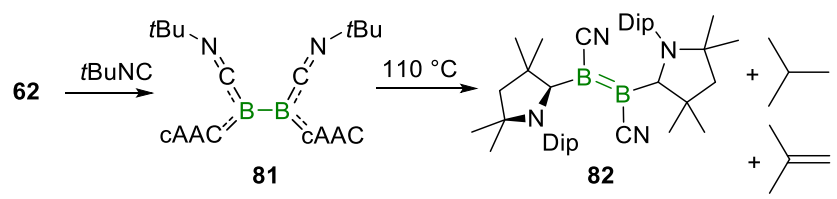

\section{Conclusion}

For an element known for its tendency to form clusters, the developments in recent years in the chemistry of electron-precise boron-boron bonds have been remarkable. New routes to B- 
B single bonds have the potential to reduce both waste and costs in the synthesis of industrially relevant diborane(4) compounds, while also allowing the construction of diboron species with new functionalities. While reductive coupling is still the most prevalent method for B-B bond formation, the hydroboration of B-B multiple bonds and the dehydrocoupling of boranes - especially that of dihydroboranes - hold some promise for future development and may even provide access to highly sought-after boron-based polymer chains. Furthermore, the salt metathesis of boryl anions with haloboranes and the metal-templated coupling of borylene fragments to form chains of boron atoms are both of interest if their scope can be widened.

Multiple bonds between boron atoms are a relatively new phenomenon and their synthesis still relies exclusively on reduction methods, such as the Wurtz coupling of NHC-stabilized dihaloboranes or the reduction of base-stabilized di- or tetrahalodiborane(6) precursors. Although their reactivity is just beginning to be established, diborenes and diborynes have already revealed a wide range of transformations, including redox chemistry, the addition of $\sigma$-bonds, cycloadditions and the activation of small molecules such as $\mathrm{H}_{2}$ and $\mathrm{CO}$. The scope for variation remains large, and with steric- and electronic-dependent reactivity patterns already emerging, it can be hoped that these species may be tuned for specific purposes. Particularly enticing avenues are the potential applications of luminescent transition metal $\pi$ diborene complexes and the substitution of $\mathrm{B}=\mathrm{B}$ units into conjugated organic molecules or materials to modify their optoelectronic properties. At the very least, boron-boron-bonded compounds seem likely to continue to provide surprises for the inquisitive chemist over the coming years.

\section{Acknowledgments}

The authors gratefully acknowledge the European Research Council (ERC) under the European Union Horizon 2020 Research and Innovation Program (grant agreement no. 669054) for a postdoctoral research position for Dr. Thomas Stennett, the Alexander von Humboldt Foundation for a postodoctoral research fellowship for Dr. Merle Arrowsmith, as well as the Deutsche Forschungsgesellschaft (DFG) and the State of Bavaria for continued support of this project. 


\section{References}

[1] E. C. Neeve, S. J. Geier, I. A. I. Mkhalid, S. A. Westcott, T. B. Marder, Chem. Rev. 2016, 116, 9091-9161.

[2] J. R. Coombs, F. Haeffner, L. T. Kliman, J. P. Morken, J. Am. Chem. Soc. 2013, 135, 11222-11231; J. Takaya, N. Iwasawa, ACS Cat. 2012, 2, 1993-2006; L. Dang, H. Zhao, Z. Lin, T. B. Marder, Organometallics 2008, 27, 1178-1186.

[3] W. K. Chow, O. Y. Yuen, P. Y. Choy, C. M. So, C. P. Lau, W. T. Wong, F. Y. Kwong, RSC Adv. 2013, 3, 12518-12539; J. F. Hartwig, Chem. Soc. Rev. 2011, 40, 1992-2002; A. Ros, R. Fernandez, J. M. Lassaletta, Chem. Soc. Rev. 2014, 43, 32293243; G. Stavber, Z. Casar, Chemcatchem 2014, 6, 2162-2174.

[4] R. J. Brotherton, A. L. McCloskey, L. L. Petterson, H. Steinberg, J. Am. Chem. Soc. 1960, $82,6242-6245$.

[5] R. J. Brotherton, A. L. McCloskey, J. L. Boone, H. M. Manasevit, J. Am. Chem. Soc. 1960, $82,6245-6248$.

[6] H. Braunschweig, R. D. Dewhurst, S. Mozo, Chemcatchem 2015, 7, 1630-1638.

[7] H. Braunschweig, R. D. Dewhurst, Angew. Chem. Int. Ed. 2013, 52, 3574-3583.

[8] M. S. Hill, Metal-Metal Bonding 2010, 136, 189-216.

[9] B. W. Pfennig, John Wiley \& Sons, Inc., Hoboken, New Jersey, 2015.

[10] a) Z. Slanina, J. Phys. Chem. 1991, 95, 1089-1091; b) R. R. Mohr, W. N. Lipscomb, Inorg. Chem. 1986, 25, 1053-1057; c) L. A. Curtiss, J. A. Pople, J. Chem. Phys. 1989, 90, 4314-4319; d) B. Ruščic, M. Schwarz, J. Berkowitz, J. Chem. Phys. 1989, 91, $4576-4581$.

[11] E. Osorio, J. K. Olson, W. Tiznado, A. I. Boldyrev, Chem. Eur. J. 2012, 18, 96779681.

[12] a) D. Y. Zubarev, A. I. Boldyrev, J. Comput. Chem. 2007, 28, 251-268; b) T. B. Tai, D. J. Grant, M. T. Nguyen, D. A. Dixon, J. Phys. Chem. A 2010, 114, 994-1007; c) A. P. Sergeeva, I. A. Popov, Z. A. Piazza, W.-L. Li, C. Romanescu, L.-S. Wang, A. I. Boldyrev, Acc. Chem. Res. 2014, 47, 1349-1358.

[13] A. Stock, A. Brandt, H. Fischer, Chem. Ber. 1925, 58, 643-657.

[14] a) T. Wartik, R. Moore, H. I. Schlesinger, J. Am. Chem. Soc. 1949, 71, 3265-3266; b) G. Urry, T. Wartik, R. E. Moore, H. I. Schlesinger, J. Am. Chem. Soc. 1954, 76, $5293-$ 5298. 
[15] a) M. Atoji, P. J. Wheatley, W. N. Lipscomb, J. Chem. Phys. 1957, 27, 196-199; b) L. Trefonas, W. N. Lipscomb, J. Chem. Phys. 1958, 28, 54-55.

[16] a) M. Atoji, W. N. Lipscomb, Acta Cryst.1953, 6, 547-550; b) M. Atoji, W. N. Lipscomb, J. Chem. Phys. 1953, 21, 172-172.

[17] H. Nöth, H. Pommerening, Angew. Chem. Int. Ed. Engl. 1980, 19, 482-483.

[18] D. A. Kleier, J. Bicerano, W. N. Lipscomb, Inorg. Chem. 1980, 19, 216-218.

[19] K. H. Hermannsdörfer, E. Matejčikova, H. Nöth, Chem. Ber. 1970, 103, 516-527.

[20] T. Mennekes, P. Paetzold, R. Boese, D. Blaser, Angew. Chem. Int. Ed. Engl. 1991, 30, 173-175.

[21] H. Klusik, A. Berndt, J. Organomet. Chem. 1982, 234, C17-C19.

[22] T. Kupfer, H. Braunschweig, K. Radacki, Angew. Chem. Int. Ed. 2015, 54, 1508415088.

[23] M. Baudler, K. Rockstein, W. Oehlert, Chem. Ber. 1991, 124, 1149-1152.

[24] a) T. Mennekes, P. Paetzold, R. Boese, Angew. Chem. Int. Ed. Engl. 1990, 29, 899900; b) W. J. Grigsby, P. P. Power, J. Am. Chem. Soc. 1996, 118, 7981-7988.

[25] H. Braunschweig, R. Shang, Inorg. Chem. 2015, 54, 3099-3106.

[26] H. Braunschweig, M. Colling, C. H. Hu, K. Radacki, Angew. Chem. Int. Ed. 2002, 41, 1359-1361.

[27] K. K. Pandey, H. Braunschweig, R. D. Dewhurst, Eur. J. Inorg. Chem. 2011, 20452056.

[28] H. Braunschweig, Q. Ye, A. Vargas, R. D. Dewhurst, K. Radacki, A. Damme, Nature Chem. 2012, 4, 563-567.

[29] S. Bertsch, H. Braunschweig, B. Christ, M. Forster, K. Schwab, K. Radacki, Angew. Chem. Int. Ed. 2010, 49, 9517-9520.

[30] K. K. Pandey, Organometallics 2011, 30, 5851-5858.

[31] H. Braunschweig, Q. Ye, A. Vargas, K. Radacki, A. Damme, Angew. Chem. Int. Ed. 2013, 52, 10657-10660.

[32] H. C. Johnson, T. N. Hooper, A. S. Weller, Top. Organomet. Chem. 2015, 49, 153220.

[33] a) E. W. Corcoran, L. G. Sneddon, Inorg. Chem. 1983, 22, 182-182; b) E. W. Corcoran, L. G. Sneddon, J. Am. Chem. Soc. 1984, 106, 7793-7800; c) E. W. Corcoran, L. G. Sneddon, J. Am. Chem. Soc. 1985, 107, 7446-7450.

[34] a) A. Wagner, S. Litters, J. Elias, E. Kaifer, H.-J. Himmel, Chem. Eur. J. 2014, 20, 12514-12527; b) O. Ciobanu, H.-J. Himmel, Eur. J. Inorg. Chem. 2007, 3565-3572; c) 
O. Ciobanu, F. Allouti, P. Roquette, S. Leingang, M. Enders, H. Wadepohl, H.-J. Himmel, Eur. J. Inorg. Chem. 2008, 5482-5493.

[35] H. Braunschweig, F. Guethlein, Angew. Chem. Int. Ed. 2011, 50, 12613-12616.

[36] S. Shimada, A. S. Batsanov, J. A. K. Howard, T. B. Marder, Angew. Chem. Int. Ed. 2001, 40, 2168-2171.

[37] H. Braunschweig, C. Claes, F. Guethlein, J. Organomet. Chem. 2012, 706, 144-145.

[38] H. Braunschweig, P. Brenner, R. D. Dewhurst, F. Guethlein, J. O. C. Jimenez-Halla, K. Radacki, J. Wolf, L. Zoellner, Chem. Eur. J. 2012, 18, 8605-8609.

[39] H. Braunschweig, R. Bertermann, P. Brenner, M. Burzler, R. D. Dewhurst, K. Radacki, F. Seeler, Chem. Eur. J. 2011, 17, 11828-11837.

[40] H. Braunschweig, F. Guethlein, L. Mailaender, T. B. Marder, Chem. Eur. J. 2013, 19, 14831-14835.

[41] C. S. Wei, C. A. Jimenez-Hoyos, M. F. Videa, J. F. Hartwig, M. B. Hall, J. Am. Chem. Soc. 2010, 132, 3078-3091.

[42] N. Arnold, H. Braunschweig, R. D. Dewhurst, W. C. Ewing, J. Am. Chem. Soc. 2016, $138,76-79$.

[43] Y. Shoji, S. Kaneda, H. Fueno, K. Tanaka, K. Tamao, D. Hashizume, T. Matsuo, Chem. Lett. 2014, 43, 1587-1589.

[44] a) Y. Shoji, T. Matsuo, D. Hashizume, M. J. Gutmann, H. Fueno, K. Tanaka, K. Tamao, J. Am. Chem. Soc. 2011, 133, 11058-11061; b) Y. Shoji, T. Matsuo, D. Hashizume, H. Fueno, K. Tanaka, K. Tamao, J. Am. Chem. Soc. 2010, 132, 82588260 .

[45] A. Huebner, M. Diefenbach, M. Bolte, H.-W. Lerner, M. C. Holthausen, M. Wagner, Angew. Chem. Int. Ed. 2012, 51, 12514-12518.

[46] T. Kaese, A. Huebner, M. Bolte, H.-W. Lerner, M. Wagner, J. Am. Chem. Soc. 2016, $138,6224-6233$.

[47] A. Huebner, A. M. Diehl, M. Diefenbach, B. Endeward, M. Bolte, H.-W. Lerner, M. C. Holthausen, M. Wagner, Angew. Chem. Int. Ed. 2014, 53, 4832-4835.

[48] A. Huebner, T. Kaese, M. Diefenbach, B. Endeward, M. Bolte, H.-W. Lerner, M. C. Holthausen, M. Wagner, J. Am. Chem. Soc. 2015, 137, 3705-3714.

[49] M. Yamashita, K. Nozaki, in Synthesis and Application of Organoboron Compounds, Vol. 49 (Ed.: E. W. Fernández, Andrew), Springer International Publishing, Switzerland, 2015, pp. 1-37.

[50] Y. Segawa, M. Yamashita, K. Nozaki, Science 2006, 314, 113-115. 
[51] Y. Hayashi, Y. Segawa, M. Yamashita, K. Nozaki, Chem. Commun. 2011, 47, 58885890.

[52] a) Y. Segawa, Y. Suzuki, M. Yamashita, K. Nozaki, J. Am. Chem. Soc. 2008, 130, 16069-16079; b) D. A. Ruiz, G. Ung, M. Melaimi, G. Bertrand, Angew. Chem. Int. Ed. 2013, 52, 7590-7592; c) H. Braunschweig, C. W. Chiu, K. Radacki, T. Kupfer, Angew. Chem. Int. Ed. 2010, 49, 2041-2044; d) J. Monot, A. Solovyev, H. Bonin-Dubarle, E. Derat, D. P. Curran, M. Robert, L. Fensterbank, M. Malacria, E. Lacôte, Angew. Chem. Int. Ed. 2010, 49, 9166-9169.

[53] L. B. Knight, K. Kerr, P. K. Miller, C. A. Arrington, J. Phys. Chem. 1995, 99, 1684216848 .

[54] T. J. Tague, L. Andrews, J. Am. Chem. Soc. 1994, 116, 4970-4976.

[55] a) M. Peric, B. Ostojic, B. Engels, J. Molec. Spect. 1997, 182, 280-294; b) M. Peric, B. Ostojic, B. Engels, J. Molec. Spect. 1997, 182, 295-308.

[56] H. Klusik, A. Berndt, Angew. Chem. Int. Ed. Engl. 1981, 20, 870-871.

[57] W. J. Grigsby, P. P. Power, Chem. Commun. 1996, 2235-2236.

[58] W. J. Grigsby, P. P. Power, Chem. Eur. J. 1997, 3, 368-375.

[59] H. Nöth, J. Knizek, W. Ponikwar, Eur. J. Inorg. Chem. 1999, 1931-1937.

[60] a) A. Moezzi, M. M. Olmstead, P. P. Power, J. Am. Chem. Soc. 1992, 114, 2715-2717; b) A. Moezzi, R. A. Bartlett, P. P. Power, Angew. Chem. Int. Ed. Engl. 1992, 31, 1082-1083.

[61] Y. Wang, B. Quillian, P. Wei, C. S. Wannere, Y. Xie, R. B. King, H. F. Schaefer, III, P. v. R. Schleyer, G. H. Robinson, J. Am. Chem. Soc. 2007, 129, 12412-12413.

[62] H. Braunschweig, R. D. Dewhurst, C. Hörl, A. K. Phukan, F. Pinzner, S. Ullrich, Angew. Chem. Int. Ed. 2014, 53, 3241-3244.

[63] P. Bissinger, H. Braunschweig, A. Damme, T. Kupfer, A. Vargas, Angew. Chem. Int. Ed. 2012, 51, 9931-9934.

[64] P. Bissinger, H. Braunschweig, A. Damme, C. Hörl, I. Krummenacher, T. Kupfer, Angew. Chem. Int. Ed. 2015, 54, 359-362.

[65] H. Braunschweig, A. Damme, J. O. C. Jimenez-Halla, T. Kupfer, K. Radacki, Angew. Chem. Int. Ed. 2012, 51, 6267-6271.

[66] H. Braunschweig, A. Damme, R. D. Dewhurst, T. Kramer, T. Kupfer, K. Radacki, E. Siedler, A. Trumpp, K. Wagner, C. Werner, J. Am. Chem. Soc. 2013, 135, 8702-8707.

[67] P. Bissinger, H. Braunschweig, A. Damme, T. Kupfer, I. Krummenacher, A. Vargas, Angew. Chem. Int. Ed. 2014, 53, 5689-5693. 
[68] P. Bissinger, H. Braunschweig, M. A. Celik, C. Claes, R. D. Dewhurst, S. Endres, H. Kelch, T. Kramer, I. Krummenacher, C. Schneider, Chem. Commun. 2015, 51, $15917-$ 15920.

[69] H. Braunschweig, A. Damme, T. Kupfer, Angew. Chem. Int. Ed. 2011, 50, 7179-7182.

[70] S. P. Green, C. Jones, A. Stasch, Science 2007, 318, 1754-1757.

[71] H. Braunschweig, A. Damme, R. D. Dewhurst, A. Vargas, Nature Chem. 2013, 5, 115-121.

[72] P. Bissinger, A. Steffen, A. Vargas, R. D. Dewhurst, A. Damme, H. Braunschweig, Angew. Chem. Int. Ed. 2015, 54, 4362-4366.

[73] a) P. P. Power, Organometallics 2007, 26, 4362-4372; b) S. Huo, X. Li, Y. Zeng, Z. Sun, S. Zheng, L. Meng, New J. Chem. 2013, 37, 3145-3151; c) Y. Peng, R. C. Fischer, W. A. Merrill, J. Fischer, L. Pu, B. D. Ellis, J. C. Fettinger, R. H. Herber, P. P. Power, Chem. Sci. 2010, 1, 461-468.

[74] a) R. Wright, M. Brynda, P. Power, Angew. Chem. Int. Ed. 2006, 45, 5953-5956; b) J. Su, X. Li, R. Crittendon, G. Robinson, J. Am. Chem. Soc. 1997, 119, 5471-5472.

[75] W. Grigsby, P. Power, J. Am. Chem. Soc. 1996, 118, 7981-7988.

[76] R. Wright, M. Brynda, P. Power, Angew. Chem. Int. Ed. 2006, 45, 5953-5956.

[77] A. Papakondylis, E. Miliordos, A. Mavridis, J. Phys. Chem. A 2004, 108, 4335-4340.

[78] L. Ducati, N. Takagi, G. Frenking, J. Phys. Chem. A 2009, 113, 11693-11698.

[79] N. Holzmann, A. Stasch, C. Jones, G. Frenking, Chem. Eur. J. 2011, 17, 1351713525 .

[80] R. Koppe, H. Schnöckel, Chem. Sci. 2015, 6, 1199-1205.

[81] M. Mitoraj, A. Michalak, Inorg. Chem. 2011, 50, 2168-2174.

[82] H. Braunschweig, R. D. Dewhurst, K. Hammond, J. Mies, K. Radacki, A. Vargas, Science 2012, 336, 1420-1422.

[83] N. Holzmann, M. Hermann, G. Frenking, Chem. Sci. 2015, 6, 4089-4094.

[84] F. Perras, D. Bryce, Chem. Sci. 2014, 5, 2428-2437; J. Grunenberg, Chem. Sci. 2015, 6, 4086-4088.

[85] D. Nelson, S. Nolan, Chem. Soc. Rev. 2013, 42, 6723-6753.

[86] F. A. Perras, W. C. Ewing, T. Dellermann, J. Böhnke, S. Ullrich, T. Schaefer, H. Braunschweig, D. L. Bryce, Chem. Sci. 2015, 6, 3378-3382.

[87] V. Lavallo, Y. Canac, C. Prasang, B. Donnadieu, G. Bertrand, Angew. Chem. Int. Ed. 2005, 44, 5705-5709. 
[88] J. Bohnke, H. Braunschweig, P. Constantinidis, T. Dellermann, W. Ewing, I. Fischer, K. Hammond, F. Hupp, J. Mies, H. Schmitt, A. Vargas, J. Am. Chem. Soc. 2015, 137, 1766-1769.

[89] J. Böhnke, H. Braunschweig, W. C. Ewing, C. Hörl, T. Kramer, I. Krummenacher, J. Mies, A. Vargas, Angew. Chem. Int. Ed. 2014, 53, 9082-9085.

[90] J. Böhnke, H. Braunschweig, T. Dellermann, W. C. Ewing, K. Hammond, J. O. C. Jimenez-Halla, T. Kramer, J. Mies, Angew. Chem. Int. Ed. 2015, 54, 13801-13805.

[91] H. Braunschweig, C. Hörl, Chem. Commun. 2014, 50, 10983-10985.

[92] a) H. Braunschweig, R. D. Dewhurst, Organometallics 2014, 33, 6271-6277; b) M. Arrowsmith, J. Böhnke, H. Braunschweig, M. A. Celik, T. Dellermann, K. Hammond, Chem. Eur. J. 2016, submitted.

[93] M. Ito, N. Tokitoh, T. Kawashima, R. Okazaki, Tetrahedron Letters 1999, 40, 55575560 .

[94] R. Kinjo, B. Donnadieu, M. A. Celik, G. Frenking, G. Bertrand, Science 2011, 333, 610-613.

[95] L. B. Kong, Y. X. Li, R. Ganguly, D. Vidovic, R. Kinjo, Angew. Chem. Int. Ed. 2014, $53,9280-9283$.

[96] M. Arrowsmith, J. Böhnke, H. Braunschweig, M. A. Celik, T. Dellermann, K. Hammond, Chem. Eur. J. 2016, submitted.

[97] R. Bertermann, H. Braunschweig, P. Constantinidis, T. Dellermann, R. D. Dewhurst, W. C. Ewing, I. Fischer, T. Kramer, J. Mies, A. K. Phukan, A. Vargas, Angew. Chem. Int. Ed. 2015, 54, 13090-13094.

[98] H. Braunschweig, P. Constantinidis, T. Dellermann, W. C. Ewing, I. Fischer, M. Hess, F. R. Knight, A. Rempel, C. Schneider, S. Ullrich, A. Vargas, J. D. Woollins, Angew. Chem. Int. Ed. 2016, 55, 5606-5609.

[99] H. Braunschweig, T. Dellermann, W. C. Ewing, T. Kramer, C. Schneider, S. Ullrich, Angew. Chem. Int. Ed. 2015, 54, 10271-10275.

[100] a) Catalytic Heterofunctionalization, Wiley-VCH Verlag GmbH, 2001; b) A. L. Reznichenko, K. C. Hultzsch, Hydroamination of Alkenes, Wiley-VCH Verlag GmbH, 2015; c) R. S. Dhillon, Hydroboration and Organic Synthesis, Springer, Berlin Heidelberg, 2007; d) S. Nishimura, Handbook of Heterogeneous Catalytic Hydrogenation for Organic Synthesis, Wiley-Interscience, 2001; e) The Handbook of Homogeneous Hydrogenation, WILEY-VCH Verlag GmbH Co. KGaA, Weinheim, 2008. 
[101] M. Hermann, C. Goedecke, C. Jones, G. Frenking, Organometallics 2013, 32, 66666673.

[102] M. I. Alexandrovna, B. I. Ionin, J. C. Tebby, Alkynes in Cycloadditions, John Wiley \& Sons, Chichester, UK, 2013.

[103] M. Arrowsmith, J. Böhnke, H. Braunschweig, M. A. Celik, C. Claes, W. C. Ewing, I. Krummenacher, K. Lubitz, C. Schneider, Angew. Chem. Int. Ed. 2016, 55, 1127111275.

[104] H. Braunschweig, T. Dellermann, R. D. Dewhurst, W. C. Ewing, K. Hammond, J. O. C. Jimenez-Halla, T. Kramer, I. Krummenacher, J. Mies, A. K. Phukan, A. Vargas, Nature Chem. 2013, 5, 1025-1028.

[105] a) F. Dahcheh, D. Martin, D. W. Stephan, G. Bertrand, Angew. Chem. Int. Ed. 2014, 53, 13159-13163; b) H. Braunschweig, R. D. Dewhurst, F. Hupp, M. Nutz, K. Radacki, C. W. Tate, A. Vargas, Q. Ye, Nature 2015, 522, 327-330; c) H. Braunschweig, M. A. Celik, R. D. Dewhurst, K. Ferkinghoff, A. Hermann, J. O. C. Jimenez-Halla, T. Kramer, K. Radacki, R. Shang, E. Siedler, F. Weißenberger, C. Werner, Chem. Eur. J . 2016, 22, 11736-11744.

[106] J. Böhnke, H. Braunschweig, T. Dellermann, W. C. Ewing, T. Kramer, I. Krummenacher, A. Vargas, Angew. Chem. Int. Ed. 2015, 54, 4469-4473.

[107] K. Takeuchi, M. Ichinohe, A. Sekiguchi, J. Am. Chem. Soc. 2012, 134, 2954-2957. 